\title{
The Smart Home: How Consumers Craft New Service Networks by Combining Heterogeneous Smart Domestic Products
}

\author{
John Harvey' (D, Mojtaba Poorrezaei ${ }^{2}$, Tony Woodall' \\ Georgiana Nica-Avram' ${ }^{D}$, Gavin Smith', Tolu Ajiboye², \\ Karina Kholodova ${ }^{2}$, and Kai Zhu ${ }^{2}$
}

(3)SAGE

\begin{abstract}
Service research suggests homes are becoming increasingly connected as consumers automate and personalize new forms of service provision. Yet, large-scale empirical evidence on how and why consumers automate smart domestic products (SDPs) is lacking. To address this knowledge gap, we analyze I3,905 consumer-crafted, automated combinations of SDPs, totaling I, I44,094 installations, across 253 separate service providers on the web service IFTTT.com. An exploratory network analysis examines the topology of the network and an interpretive coding exercise reveals how consumers craft different styles of human-computer interaction to cocreate value. The results reveal that the SDP network is disassortative, is imbalanced, has a long-tailed degree distribution, and that popular services have high centrality across all product category combinations. We show that popular combinations of SDPs are primarily motivated by utilitarian value-seeking enacted through a preference for automated tasks outside of conscious attention, though more individualistic combinations are slightly more likely to be hedonistically inclined. We conclude by showing how these consumer-crafted forms of service provision within domestic environments reveal design redundancy and opportunities for service innovation.
\end{abstract}

\section{Keywords}

smart home, Internet of Things, craft consumers, big data, service design

The purpose of a computer is to help you do something else. The best computer is a quiet, invisible servant.

Weiser (1996)

Service research highlights the importance of smart technologies and artificial intelligence in transforming frontline service delivery (Huang and Rust 2018; Jörling, Böhm, and Paluch 2019; van Doorn et al. 2017). Early literature (Bitner, Ostrom, and Meuter 2002; Meuter et al. 2000) describes self-service technologies situated in commercial locations (e.g., ATMs in a bank, self-checkout services in a supermarket, or service robots in hotels) or alternatively accessed via telephone or online. However, as computing devices have become ubiquitous, always "on," and embedded in a widening range of products, the scope for "smart interactive services" (Wünderlich, Wangenheim, and Bitner 2013) or "frontline service technology infusion" (De Keyser et al. 2019) has blurred the boundaries of service encounter. The domestic environment has not escaped these pervasive technologies, and the home is now the physical frontline for many forms of service innovation, where smart products compete for the role of "quiet, invisible servants" (Weiser 1996).
Service innovation research is an area of expanding interest (e.g., Gustafsson, Snyder, and Witell 2020; Helkkula, Kowalkowski, and Tronvoll 2018; Hollebeek and Andreassen 2018). This article focuses on "smart home" service innovation and its relationship to smart domestic products (SDPs). We follow Woodall, Rosborough, and Harvey's (2018) definition of SDPs "as technological interfaces that provide or support any type of home service and are embedded into domestic routines." SDPs - also called "smart home technologies" (Wilson, Hargreaves, and Hauxwell-Baldwin 2017) or "smart home objects" (Stojkoska and Trivodaliev 2017) - are "smart" because they differ from "dumb" or "operand" (Vargo and Lusch 2004) resources as technologies that act rather than waiting to be acted upon. Instead, they perform as independent relays or

\footnotetext{
'N/LAB, Nottingham University Business School, Jubilee Campus, University of Nottingham, United Kingdom

${ }^{2}$ Marketing Department, Nottingham Business School, Nottingham Trent University, United Kingdom

\section{Corresponding Author:}

John Harvey, N/LAB, Nottingham University Business School, Jubilee Campus, University of Nottingham, Nottingham NG7 2RD, United Kingdom. Email: john.harvey2@nottingham.ac.uk
} 
catalysts with the potential for facilitating long chains of causal connections between functions inside and outside the home. Connections may be between systems owned solely by one consumer, between different consumers, or between consumers and service providers (e.g. companies, charities, or governments).

Recent literature reviews (Alam, Reaz, and Ali 2012; Gram-Hanssen and Darby 2018; Marikyan, Papagiannidis, and Alamanos 2019) have shown there are broadly four types of study currently deployed in smart home research. GramHanssen and Darby (2018) characterize these as the following: conceptual -where meanings are ascribed to "smartness," the "home," and the relation between technology and myriad actors; technical - how distinct elements communicate with one another and how hardware/software is designed; prospective - future smart home potential: what is possible, and how it might be configured for optimal benefit; and last, evaluative-which smart devices are connected, and how smart homes work in practice. Of the four types, they note evaluative is the least studied, primarily due to a lack of available data. These reviews highlight the lack of large-scale or longitudinal empirical research into how smart technologies actually work in domestic environments. We aim to address this gap using a massive observational data set of consumer-led service innovation $(1,144,094$ instances) to investigate the value derived by craft consumers in smart home improvement. We evaluate (1) how such consumers connect SDPs into broader networks of service provision and (2) how these connections translate into functionalities cocreated by connecting heterogeneous SDPs.

We begin by surveying the literature on smart homes, SDPs, service innovation, and craft consumers. Subsequently, we discuss application programming interfaces (APIs) as a way that organizations provide modular access to services that consumers can modify. We then introduce online service platform IFTTT.com, the source of data for this study, to illustrate how consumers combine heterogeneous SDPs using APIs to create new forms of service provision. After this, we outline our research approach which deploys the following: (1) an exploratory network analysis on the SDP network and (2) an interpretive coding exercise to analyze the types of human-computer interaction and the values expressed by consumers on If This, Then That (IFTTT) when crafting new forms of service provision. Our results are derived first from a range of analyses focused on a topological analysis of a network of 253 separate services. Next, we explore why craft consumers connect SDPs in the way they do by analyzing the benefits that users derive from connecting devices via IFTTT. Our results are expressed as a series of "key insights." By combining both approaches, our insights identify directions for SDP service research and design, and we present these in the final section.

\section{Smart Homes and SDPs}

The term "smart" in natural speech is used to convey quickwittedness or high intelligence (Cambridge Dictionary 2019).
Transposing this term into the field of domestic service innovation implies the use of products beyond direct householder intervention. Human involvement is required for the installation of the products concerned, but once set up, these operate autonomously and are independent of the reflective mind. Such products take care of a wide range of domestic concerns ranging from energy use, comfort, leisure, health care, safety, and security (Alam, Reaz, and Ali 2012). For "smart," in domestic terms, it is conventional to think of (a) smart homes - the context on which "smartness" is focused and (b) smart objects (or products) - the technologies used to embed smartness in the home (Wünderlich et al. 2015). Beyond this though, the smart products within the smart home integrate with other smart contexts - smart grids, smart communities, and smart citiesinterconnected via the Internet of Things (IoT; Ashton 2009). The IoT is a computer-mediated network of distributed artificial intelligence existing in parallel with the regular internet. It has been estimated that by 2020 , this network will comprise 25 billion separate smart products (Miranda et al. 2015).

A home becomes smart when it has "a high level of device connectedness within and beyond the home, along with a reliance on that connectivity for everyday operations" (GramHanssen and Darby 2018, p. 96). "Context awareness" (Gu, Pung, and Zhang 2015) is critical for interaction between a home and any smart products it contains, and Figure 1 demonstrates how context awareness can be configured. This illustrates an idealized smart home, showing classes of smart products currently available and where these are typically located. SDPs, the term we use to denote these technologies, was first used in Woodall, Rosborough, and Harvey (2018). Other terms denoting this same phenomenon are "smart home technologies" (e.g., Wilson, Hargreaves, and HauxwellBaldwin 2017), "smart home objects" (e.g., Stojkoska and Trivodaliev 2017), or "smart home devices" (e.g., Robles et al. 2010). We use the word "product" rather than object, device, or technology to indicate a strong relationship with consumer markets, and to acknowledge, these may be individual units or systems and may be virtual or physical. By deploying "domestic" rather than "home," we draw on the work of Elizabeth Shove and colleagues (e.g., Hand and Shove 2007; Shove 2003; Watson and Shove 2008) who use this to connect everyday practice with its location.

Smart homes can either be built deliberately or retrofitted post hoc as smart products become embedded in older houses. The public perception of SDPs is largely positive (Wilson, Hargreaves, and Hauxwell-Baldwin 2017), yet according to Olick (2017), although 80 million smart products were sold worldwide in 2016 (a 64\% increase on the previous year), evidence suggests few people are prepared to pay a premium for a either a built smart home or one that has been expensively converted. The increasing volume, therefore, is explained primarily by retail sales of individual units used by consumers to upgrade houses they occupy. The number of planned smart domestic spaces is much smaller than the number of homes where this iterative upgrading will, for many years, be the norm. 


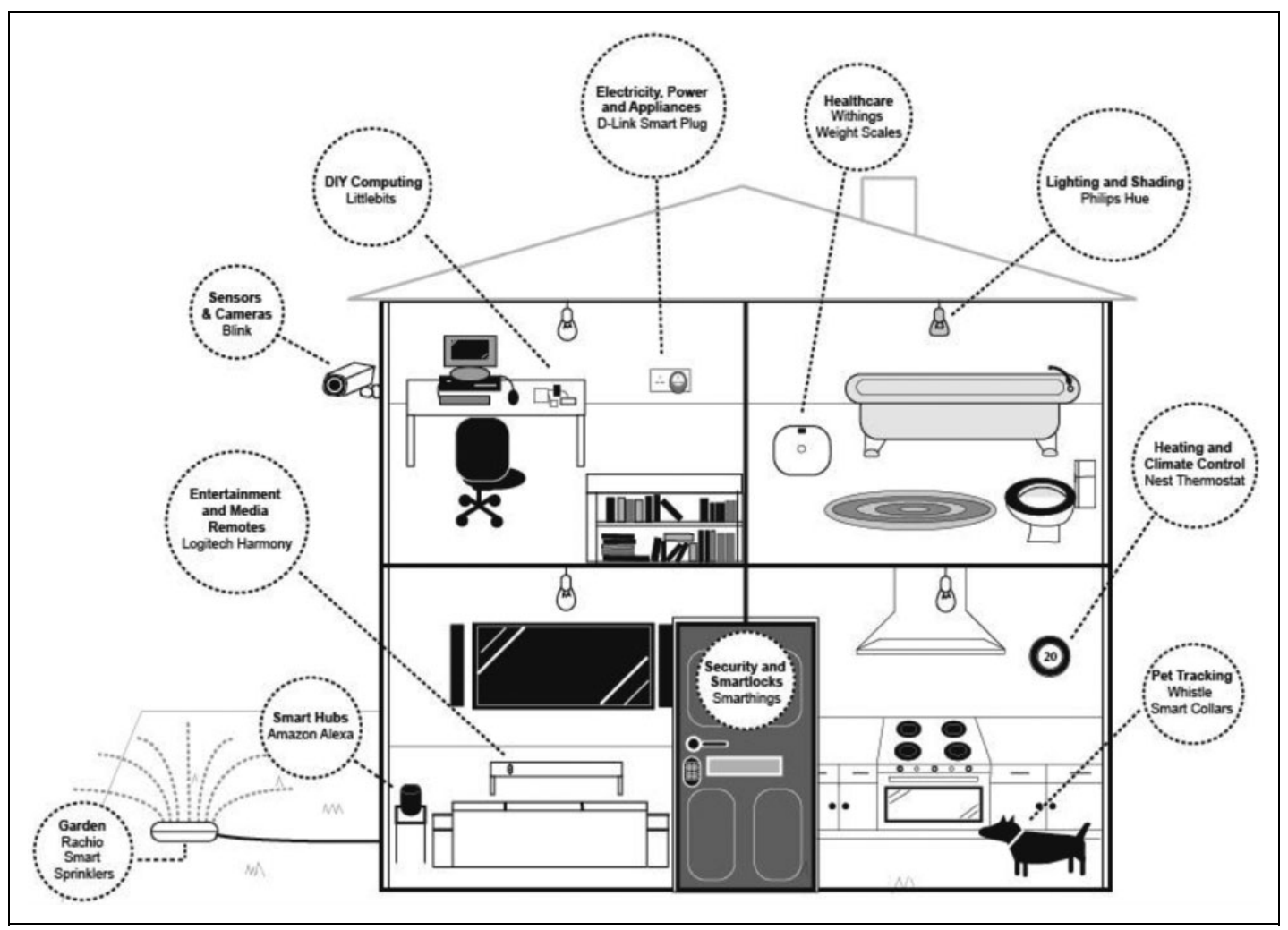

Figure I. An overview of smart domestic product classes with examples.

We refer to this iterative upgrading as Do-It-Yourself (DIY) smartness - following Gram-Hanssen and Darby (2018). This might involve the purchase of a single product (e.g., Amazon Echo, Nest Thermostat, Ring video doorbell) or multiple products with no aim other than to deploy the novelty these products convey, allowing for "... more interaction, playing and personalizing..." (p. 100) of domestic technological potential. Alternatively, though, there are those for whom "smart" potential becomes a challenge in itself and for whom this challenge becomes an act of creativity (see, e.g., Funk et al. 2018; Haraty, McGrenere, and Bunt 2017). This resonates with Campbell's (2005) notion of the craft consumer, someone who typically deploys skill, knowledge, passion, and judgment within a context of self-expression, or self-transformation (Elliot 2016), that moves beyond mere personalization of context and space.

SDPs are a special case of the wider category, humancomputer interface (HCI; Laurel and Mountford 1990)-a device or program enabling users to communicate with a computer. Woodall, Rosborough, and Harvey (2018) categorize SDPs via a $3 \times 3$ matrix typology; first, according to the form of HCI enacted (either supportive, advisory, or persuasive) and second with the type of value derived from the SDP (defined as either transformative, utilitarian, or hedonic value). Various HCI forms have emerged over the past two decades and can be divided according to the extent that they intervene into user consciousness. For instance, some interactions happen in the background not requiring conscious attention to the changing environment (e.g., a light automatically dimming as a person leaves a room). These supportive interactions aim to get out of the way of the user and in HCI literature are called "calm" technology (Weiser and Brown 1997). As Weiser (1991, p. 94) noted "The most profound technologies are those that disappear. They weave themselves into the fabric of everyday life until they are indistinguishable from it." Other HCI forms deliberately try to catch the user's attention to initiate an informed decision and are thus advisory (e.g., receiving a notification on a smartphone whenever motion is detected on a security camera). Finally, some HCI forms seek to deliberately manipulate users into acting, such that they are consciously aware, but nonetheless motivated to act in a way that they wouldn't without prompt (e.g., smart watches vibrating to ensure their owners move and burn calories). This form of HCI is referred to as persuasive computing (or "captology"-computers as persuasive technology; Fogg 1998).

The vertical axis of Woodall, Rosborough, and Harvey's (2018) typology comprises three archetypal value forms. Two of these, hedonic and utilitarian are widely deployed in the marketing literature (e.g., Babin, Darden, and Griffin 1994; Chitturi, Raghunathan, and Mahajan 2008; Das, Mukherjee, and Smith 2018). For SDPs, utilitarian value relates to the perceived benefits of delegating routine, domestic endeavors (e.g., Brich et al. 2017). Hedonic value, by contrast, relates to outcomes that delight, surprise, or excite. The third form refers to outcomes for personal or social well-being and is named transformative value (Blocker and Barrios 2015). This relates to agendas described in Mick (2006) but is used here 


\begin{tabular}{|c|c|c|c|}
\hline INTENTION & Supportive & Advisory & Persuasive \\
\hline VALUE-TYPE & $\begin{array}{c}\text { Calm technology } \\
\text { (Weiser and Brown, 1997): } \\
\text { designed to sustain existing } \\
\text { behavior }\end{array}$ & $\begin{array}{l}\text { Technology designed to help } \\
\text { customers determine their } \\
\text { own behavior }\end{array}$ & $\begin{array}{l}\text { Captalogical technology } \\
\text { (Fogg 1998): } \\
\text { designed to change or create } \\
\text { new behavior }\end{array}$ \\
\hline Transformative & \multirow[b]{2}{*}{ TS } & \multirow[b]{2}{*}{ TA } & \multirow[b]{2}{*}{ TP } \\
\hline $\begin{array}{l}\text { Focus on } \\
\text { personal or social } \\
\text { wellbeing }\end{array}$ & & & \\
\hline Utilitarian & \multirow[b]{2}{*}{ US } & \multirow[b]{2}{*}{ UA } & \multirow[b]{2}{*}{ UP } \\
\hline $\begin{array}{c}\text { Focus on } \\
\text { daily/routine domestic } \\
\text { endeavor }\end{array}$ & & & \\
\hline Hedonic & \multirow[b]{2}{*}{ HS } & \multirow[b]{2}{*}{ HA } & \multirow[b]{2}{*}{ HP } \\
\hline $\begin{array}{l}\text { Focus on the } \\
\text { provision of hedonic } \\
\text { benefits }\end{array}$ & & & \\
\hline
\end{tabular}

Figure 2. A matrix of smart service innovation opportunities.

specifically in relation to the domestic environment. When Woodall, Rosborough, and Harvey's (2018) two dimensions are conjoined (Figure 2), they create a matrix that helps illustrate the wide variety of smart possibilities. Combinations can be applied both to individual objects with smart utility and to the broader smart service systems into which these might be integrated. The matrix helps identify innovation possibilities for service designers who can implement combinations of value and HCI (e.g., [Transformative/Supportive], UA [Utilitarian/Advisory], HP [Hedonic/Persuasive]) to suit potential market opportunities.

\section{Service Innovation and the Craft Consumer}

Service innovation is "the creation of new value propositions by means of developing existing or creating new practices and/ or resources, or by means of integrating practices and resources in new ways" (Skålén et al. 2015). This definition configures service innovation as a practical accomplishment, and in the context of DIY, smartness brings the homeowner sharply into focus, someone who both (co)creates and consumes the smart services they develop. The "working consumer" (Cova and Dalli 2009) trope has a well-established provenance within service research. This emerges from different academic traditions but generally describes the consumer as either "dupe" or "hero" (Slater, in Campbell 2005, p. 23/24), meaning we either control, or are controlled by, our consumption habits. Over the past 40 years, researchers have drawn attention to the overlap of production and consumption in customer experiences (e.g., Toffler's, 1980, “prosumer”; Firat and Venkatesh's, 1995, "postmodern consumer"), while others have shown how the productive potential of market actors might be harnessed (e.g., Prahalad and Ramaswamy 2000). Similar ideas appear in Vargo and Lusch (2004) where a shift from a product- to a service-dominant marketing logic (SDL) has become influential. Using a broadly service-for-service exchange analogy, SDL posits service innovation resulting from the integration of diverse shared resources, either operant (with power to act) or operand (to be acted upon), to form value in the shape of varied service benefits. Service innovation is perceived primarily as customer driven with information and digital resources increasingly relevant to how value is understood and distributed within markets (Barrett et al. 2015). A later shift in emphasis from coproduction to cocreation (Vargo and Lusch 2006) acknowledges some weakness in earlier arguments.

The distinction between cocreation and coproduction is highly relevant to this study, as these frame the consumer in different roles (Hilton, Hughes, and Chalcraft 2012). For example, as a "more general concept" (Galvagno and Dalli 2014) cocreation suggests, even passive consumer/supplier interactions (e.g., sitting on a train) are collaborative in that all service experiences are moderated by both consumer character and the involuntary inflections that configure them. Coproduction, in contrast, implies a service does not happen in any substantive sense unless the consumer participates in its performance and completion (e.g., Etgar 2008). The latter has pejorative implications if consumers become nonremunerated part-time employees for a firm - that is, the "dupe"-undertaking for free, activities for which others would traditionally have been paid (e.g., Cova, Dalli, and Zwick 2011; Humphreys and Grayson 2008; Ritzer 2016). This might be putting together a furniture kit or self-swiping groceries at the supermarket. Alternatively, though, this could provide opportunities for the consumer (as "hero") and where prosumption/coproduction is 
envisaged as "more proactive and critically engaged" behavior (Knott 2013) enabling rather than constraining the consumer and facilitating the cocreation of value in the process (Chandler and Chen 2015). This is reflected in Campbell's (2005) notion of the craft consumer, an exemplar case of the creative prosumer for whom consumption is characterized by participation, skill, and mastery: "the assumption here is that individuals consume principally out of a desire to engage in creative acts of self-expression" (p. 24).

Craft consumers are those who typically find pleasure in creative practices such as cookery and gardening and who both design and build - in the broadest sense - that which they consume (Campbell 2005). Campbell suggests, "the craft consumer is a person who typically takes any number of massproduced products and employs these as the raw materials for the creation of a new 'product' ... typically intended for selfconsumption" (p. 27/28). For "product," we might say "outcome," given that both services and experiences are now the lingua franca of contemporary consumption practice (e.g., Bolton et al. 2014; Carú and Cova 2006). Elliot (2016) suggests craft consumption is reflexive and thus transformational, heightening engagement and social relatedness. Craft consumption is similar to craft production in that people are expressing a preference to do work for themselves rather than pay others to do it for them (Cole 2018; Kosnik 2018), and both can have function and meaning in consumers' everyday lives. Also typical of the genre is home-improvement work, and both Watson and Shove (2008) and Wolf and McQuitty (2011) show how painting and decorating fit into and help distinguish this category. Of increasing interest, though, is how DIY work transcends traditional boundaries taking opportunities made available via the Web (Beer and Burrows 2010; Novak and Hoffmann 2019; Paltrinieri and Espoti 2013). We address this in the section that follows.

\section{The Research Context: IFTTT}

Ethnographies within service and design research have long shown that technologies are appropriated and adapted in ways that designers had not previously intended. Appropriation is a learned behavior that supports resource integration (Hibbert, Winklhofer, and Temerak 2012) and is widely seen as necessary to consumer engagement (e.g., Chandler and Lusch 2015). Indeed, two recent service research papers have called for further study into how service innovation can be triggered by changing resource integration and cocreation roles (Helkkula, Kowalkowski, and Tronvoll 2018; Jaakkola and Alexander 2014). And yet, as Dix (2007) notes, designing for forms of appropriation and innovation based on the unexpected seems an oxymoron. How can service providers facilitate something they cannot yet imagine consumers will want? One increasingly popular approach is to make available APIs for products that consumers can access and configure. APIs specify how software components should interact, and these enable the features of respective smart products to be digitally modularized (e.g., turning a light on or off) and thus algorithmically accessible at the behest of consumers. APIs afford the potential for creating modularity in service design, allowing consumers to craft their own new forms of service provision and tailor an experience to suit their personal needs and taste (DIY).

An API is a means by which the technical features of an SDP can be interacted with remotely, and potentially, combined with other technologies to create chains of events that "trigger" each other and enable vertical integration of functionalities (Chase 2013). For example, when a person leaves home to go to work, their mobile phone can use geo-positioning to sense they have left and create a trigger causing their digital thermostat to reduce ambient house temperature, saving money and conserving fuel without user intervention. IFTTT is one of several online automated task services (Hoy 2015) used for combining APIs from popular software applications and hardware. IFTTT is the most popular of these services (Desolda, Ardito, and Matera 2017). User-designed connections between applications are referred to as recipes that each involve a distinct set of ingredients and contextual factors to be adhered to: If a specific "trigger" happens to $X$, then outcome $Y$ ("action") follows.

IFTTT recipes represent a vast cosmos of user-led innovation in service design and innovation outside the realm of traditional market research-led product development cycles (Ovadia 2014). Indeed, though some savvy companies are now creating recipes for consumers, the majority are designed and publicly shared by consumers. This newly emerged platform has huge potential, giving imaginative prosumers almost limitless opportunity for cocreating DIY smartness. The list of IFTTT smart product APIs (also called channels) and associated recipes is thus constantly growing. Many recipes represent highly individualized personal projects, while others have proven useful to tens of thousands of other people. Figure 3 illustrates the structure of IFTTT recipes and reveals the implicit network structure that forms between channels. The topology of the network (the way in which its constituent parts are arranged and interrelated) gives the most immediate empirical evidence of how consumers appropriate SDPs and craft new forms of service value beyond the original designer's intent.

\section{Research Questions}

The IFTTT recipe database contains a wealth of behavioral data on consumer-led service design, yet research on this form of craft consumption is lacking. Although studies exist in computer science and human-computer interaction journals that focus on technical characterizations (e.g., Mi et al. 2017; Ur et al. 2016) or privacy (e.g., Fernandes et al. 2017; Surbatovich et al. 2017), the services literature has not yet examined how these services form value for users. For instance, how people decide what products to connect and the functionalities they cocreate have not to our knowledge been studied. Our research design combines topological network analysis and a subsequent interpretive coding exercise of a longitudinal data set. Our aim is to understand how a community of craft consumers practice service innovation and value cocreation in an 


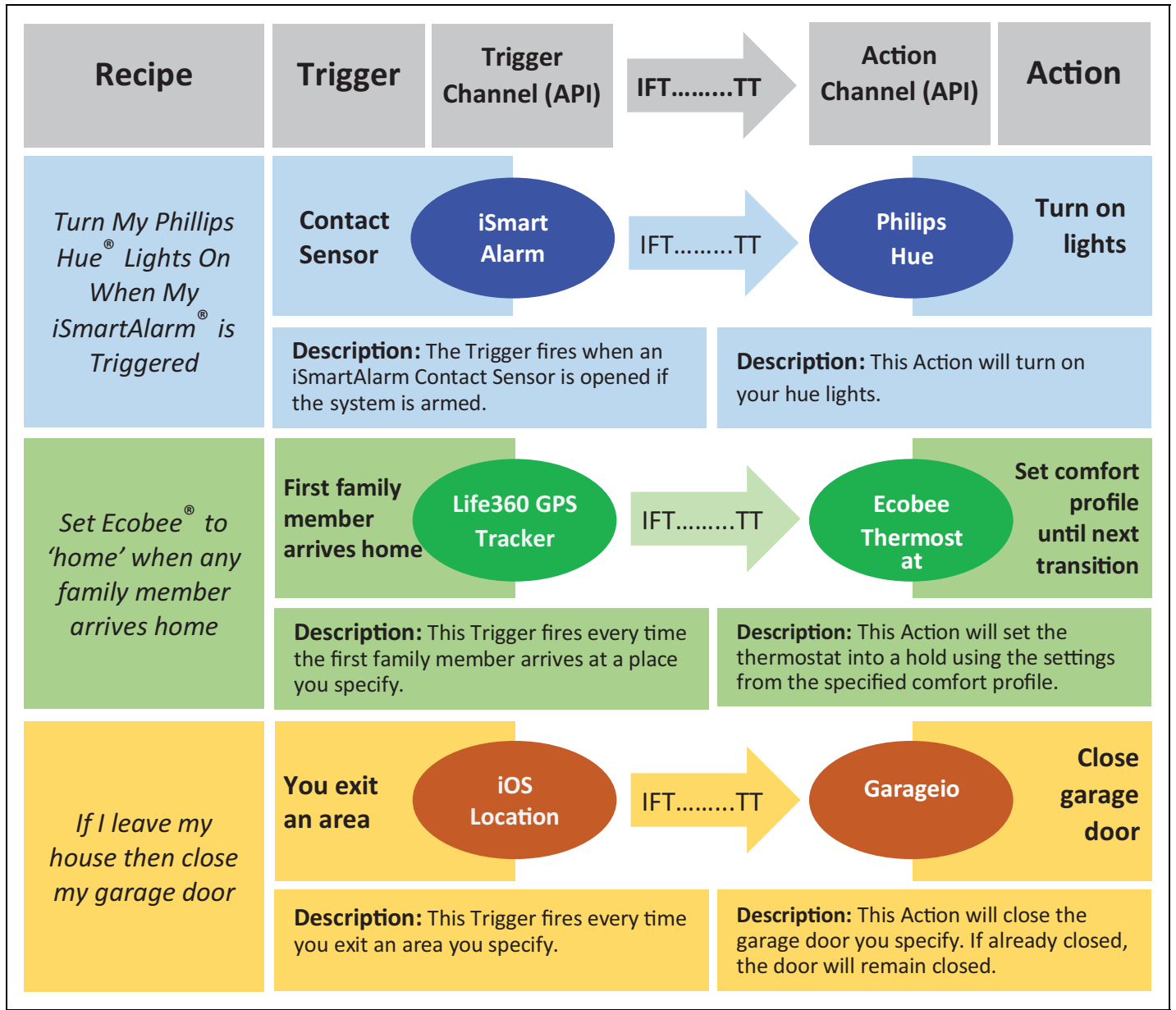

Figure 3. Illustrative examples showing structure of If This, Then That (IFTTT) recipes.

emergent context (IFTTT) facilitating DIY domestic smartness. We set the following research questions:

Research Question 1: How do craft consumers connect $S D P$ s to cocreate value within a broader network of service provision?

Here, we explore the topology of the SDP/IFTTT network. This is in response to calls to address the lack of empirical evidence on how consumers craft new service design by integrating heterogeneous products in the home (Alam, Reaz, and Ali 2012; Gram-Hanssen and Darby 2018; Marikyan, Papagiannidis, and Alamanos 2019). Findings have clear implications for how service providers think about important but paradoxical considerations of innovating by "designing for appropriation" (Dix 2007).

Research Question 2: What functionalities do smart home craft consumers cocreate by connecting heterogeneous $S D P$ s?

This question is not focused just on how SDPs are connected but examines also the concomitant motivational states underlying product connectivity and new forms of service provision.
We draw on Woodall, Rosborough, and Harvey's (2018) typology to categorize IFTTT recipes according to archetypal value forms and the means of human-computer interaction which enable these. The findings can help contribute to understanding how service innovation can be triggered by consumer-led resource integration (as called for by Helkkula, Kowalkowski, and Tronvoll 2018; Jaakkola and Alexander 2014).

\section{Research Method}

Much of the previous work on SDPs has focused on attitudes to these products and on the social practices that apply (see, Marikyan, Papagiannidis, and Alamanos 2019). Although this work is valuable, we propose that to understand fully how SDPs are deployed in practice requires the analysis of large-scale historical and behavioral data. Such data can be used to inform abductive reasoning and theorization about the emergence of smart craft consumption and associated new service development (Gram-Hanssen and Darby 2018). Abductive work is not the norm in marketing research, which has been dominated by hypothetico-deductive approaches (Hofacker, Malthouse, and Sultan 2016). However, there is growing interest in abductive reasoning (e.g., Antons and Breidbach 2018) given the emergence of "big data" that can provide unprecedented and 
naturalistic insights into behavior exhibited by consumers and service providers alike.

\section{Data Collection}

Both research questions are pursued via analysis of a largescale data set acquired by scraping the IFTTT home page for all recipes in its library. This repository captures details of craft consumer behavior played out in natural settings. Ur et al. (2016) originally scraped this data, and we are indebted to them for making their results open access. From an aggregated data set comprising 295,156 recipes and 259 channel APIs, we checked each channel to determine whether they could be categorized as SDPs based on classes outlined in Figure 1. Once the list of SDPs was collated, we filtered recipes to only include those used as either a trigger channel and/or an action channel. This process was necessary to isolate the smart home subgraph for IFTTT and permit further analysis specifically on products used to modify the domestic environment. We retain nondomestic channels where they trigger a smart domestic action channel (e.g., mobile phone GPS measurement triggering central heating in the home when a person leaves work) or when a SDP triggers a channel outside the home (e.g., push notification sent to a mobile phone when a thermostat records a temperature above a specified limit). Once filtered, the network comprised 253 individual channels and 13,905 recipes, accounting in total for 1,144,094 IFTTT installations. Craft consumers in this context fall on a continuum - at one extreme are those for whom smart recipe generation is the object of engagement, while at the other extreme are those for whom smart home development is the primary aim. The first we describe as developers and the latter as downloaders. For developers, recipe configuration provides value as an act of cocreation in itself, and for both developers and downloaders, further value is cocreated by modifying their homes.

\section{Methods of Analysis}

IFTTT data are analyzed using two separate but empirically associated methods. First, we perform a range of exploratory network analyses designed to identify the patterns of connection cocreated by recipe developers. Second, we undertake an interpretive coding exercise to explore how these patterns emerge as functionalities deployed by craft consumers to cocreate smart domestic contexts. Each method is now discussed in turn.

\section{Exploratory Network Analysis}

The first analytical phase of our study is exploratory network analysis (De Nooy, Mrvar, and Batagelj 2018). Analytical software used included Ucinet, Pajek, and Python Networkx (see Batagelj and Mrvar 1998; Borgatti, Everett, and Freeman 2002; Borgatti, Everett, and Johnson 2018). Network visualizations came from a modified version of Gephi (see Bastian, Heymann, and Jacomy 2009). The IFTTT recipes are modeled as a directed network where nodes represent channels and edges are recipes crafted between them. A sequence of global and local network measures reveals both the relative position of SDPs within the network and the structure of the network in its entirety. The measures are as follows: (1) basic structural measures, examining the geodesic distance and giant connected component (i.e., which products have been combined in recipes and what structures are formed in the aggregate SDP network); (2) degree distributions, revealing how similar in popularity are those products connected into recipes; (3) centrality measures, indicating the relative positional "importance" of SDPs facilitating connections between other products. Centrality denotes the extent to which a node contributes to network structure by virtue of its position within the network (Kang et al. 2011). We include measures of betweenness centrality, closeness centrality, and also PageRank centrality to find which products are connected to other highly connected products through recipe development. And (4) we address degree assortativity, to determine whether products that are similar form connections with each other (as in "birds of a feather flock together") or whether products with few connections tend to link to highly connected products. In directed networks, each node $i$ is characterized by an incoming $k$ in-degree and an outgoing $k$ out-degree. Assortativity can therefore be defined by four degree correlation functions (inin, in-out, out-in, and out-out; Barabási 2016) using the Pearson correlation coefficient between degrees found at the two ends of a link. Collectively, these subquestions address the structural elements of value-forming potential within the network.

\section{Interpretive Coding Exercise}

Research Question 2 concerns the functionality that craft consumers derive from connecting SDPs. To answer this, we designed an interpretive coding exercise for analyzing (1) how IFTTT users characterize their value-related motivations for creating recipes and (2) the form of human-computer interaction enabling such value. The most frequently downloaded recipes were first selected for analysis from the initial pool of 13,905 . Analysis showed that the number of recipes with 100 or more downloads was 1,170 , representing $89.93 \%$ of all SDPrelated activity on IFTTT. This "most popular" subset represents the activities of those users we describe as downloaders. A second area of interest was recipes representing the activities of those users closest to the developer end of the distribution (1-99 downloads) and comprised 11,835 different recipes but only $10.07 \%$ of overall downloads.

Given the broadly logarithmic character of the download distribution, we treated the $100+$ downloads data set as broadly homogeneous and below 100 as heterogeneous. This latter group we subdivided into five bins- 1 download $(2,992$ recipes), 2-24 downloads (7,918 recipes), 25-49 (1,109 recipes), 50-74 (454 recipes), and 75-99 downloads (260 recipes). Although we had no strong evidence on which to base an associated (and thus, testable) hypothesis concerning relative differences in character between recipes at different points 


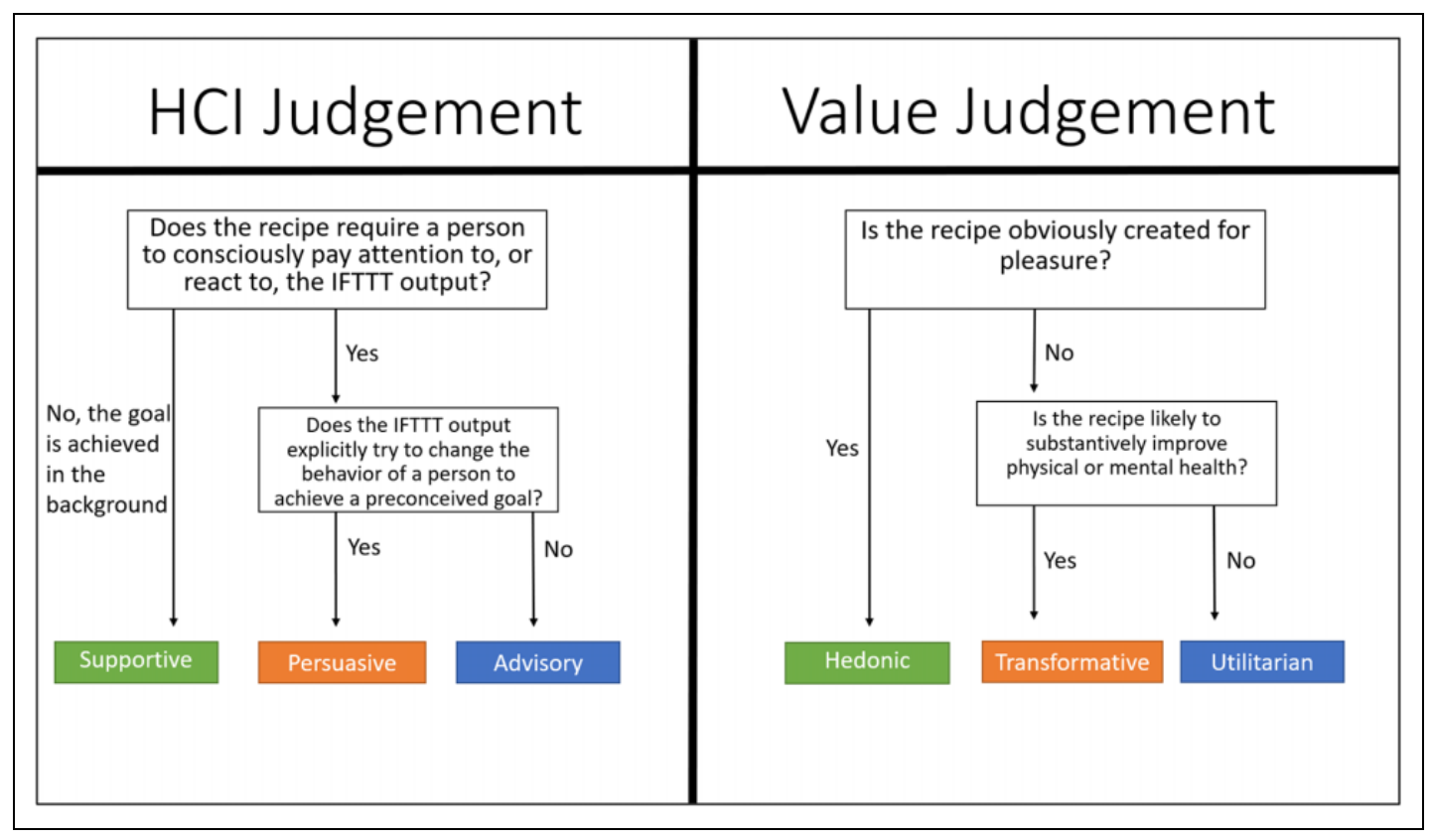

Figure 4. Decision tree developed by the authors for human-computer interface and value judgment.

along the developer/downloader continuum, we believed adopting this position would offer good potential for exploratory analysis. Taking one-download recipes as a bin of its own was clearly justified given the comparatively high number of recipes at that level.

Two coders, $\mathrm{PhD}$ marketing students, were recruited and trained to understand the IFTTT-SDP data set. The first phase was thus preparation for coding. Each recipe contains details across a number of fields: (1) author-entered description (what the recipe does and why it is useful), (2) trigger channel (which API causes the recipe to occur), (3) trigger description (which specific channel feature initiates the recipe), (4) action channel (which API is activated and thus causes the channel to act), and (5) action description (which specific action channel feature is activated). Based on an analysis of 150 randomly selected recipes, the principal authors created a coding protocol to assist coders in interpreting the functional motivation and HCI style evident in each recipe. The protocol was designed to maximize intercoder reliability, and from this, a decision tree was developed (Figure 4). Following Woodall, Rosborough, and Harvey's (2018) SDP typology, the decision tree guided coders to characterize each individual recipe in each of the two parts of the IFTTT-SDP database (developer-focused and downloader-focused) based on (a) the nature of technology-human relationships (HCI judgment) and (b) perceived value type.

Working independently, coders were given an initial batch of 500 recipes to evaluate from the downloader-focused data set. We adopt Krippendorff's $\alpha$ to determine the level of intercoder reliability. This method was used because it allows for uniform reliability standards and is insensitive to number of values per variable, number of observers, sample size, or missing values (Krippendorff 2018). The intercoder reliability for both HCI and value type judgment in this first phase was .76 and .79, respectively ( $80 \%$ similarity). Krippendorff (2018) suggests an acceptable level of reliability occurs above $\alpha \geq .667$, and given our objective was to maximize sample size for subsequent analysis, these results provided confidence to continue.

In a second phase, coders were given the remaining recipes (670) from the downloader-focused data set for independent coding. Krippendorff's $\alpha$ for this second task was .79 and .80 for HCI and value sides, respectively, figures at, or close to, the expected norm for a "good" intercoder reliability test (e.g., De Swert 2012). Combining the two phases, there were 974 (from $1,170)$ perfect matches between the two coders (83\% similarity). The result presented strong evidence for (a) robustness of the decision tree and (b) good intercoder reliability. This left only 176 unresolved recipes. Investigations suggested that in this relatively small but significant subsample decisions had proved difficult because although the IFTTT website readily identified function to be performed, it was not always clear why the user wished the function to be performed. Thus, there were instances where coders disagreed whether HCI was advisory or persuasive, and value type was transformative or utilitarian. In order to achieve $100 \%$ concurrence between coders (to maximize sample size for the next stage of the analysis), coders were asked to collaboratively recode the 176 recipes they had independently disagreed on, either for the HCI side, the value side, or both. As these were public/shared recipes, we adopted a downloader perspective and a decision protocol based on "most likely" developer intent.

The SDPs within these recipes were also manually labeled into broader categories based on manufacturers' descriptions to distinguish normal application as either inside or outside the domestic boundary - that is, is each smart product designed for a domestic environment (or not) and what is the product designed to do (e.g., heating, lighting, security, entertainment)? 
The purpose of labeling was to determine direction of causality for SDP-related recipes: Are SDPs primarily acted upon by channels triggered outside of the home, do SDPs act as a trigger to act upon channels outside of the home, or do SDPs act within the home itself by forming an internal subgraph of connections between products. Labeling also provides further contextual depth for examining the relationship between categories of heterogeneous products - that is, which aspects of service provision are combined when consumers craft new recipes.

Finally, we asked coders to evaluate the developer-focused data set using the same methods used for the downloaderfocused data set (independent evaluation followed by collaborative coding to resolve differences). A sample size of 120 was selected for each subgroup bin. This enables a small-tomedium effect size (index of 3.2; Cohen 1992) to be observed with $80 \%$ power when considering per cell/aggregate cell changes in one versus rest proportions. In practice, this means if differences (increases) in cells with proportions closest to .5 exist, they will be observed with $80 \%$ power. The coders achieved $91 \%$ coding similarity on this additional 620 -recipe sample before collaboratively resolving those outstanding. Our research design, focused on two primary research questions, is summarized at Table 1.

\section{Findings}

\section{Research Question I}

This question is concerned primarily with the topology of the IFTTT-SDP network and describes key insights derived from exploratory network analysis using a range of software tools designed for that purpose. Table 2 provides a description of the network by identifying key characteristics.

Key Insight 1: A small number of channels capture a large share of installations. The SDP network exhibits long-tailed degree and weighted degree distributions.

The SDP network has highly right-skewed degree distributions and weighted degree distributions. Figure 5 (A and B) shows that some SDPs have gained many more connections than others in both numbers of separate product connections (recipes) and numbers of installations associated with those connections. Channels such as Nest Thermostat (out-degree 86) and Phillips Hue light bulb (in-degree 153) have accrued many more connections to other channels when viewed comparatively. The long-tailed nature of the degree distribution is similar to other social, biological, and technological networks examined by previous research (e.g., Albert and Barabási 2002; Dorogovtsev and Mendes 2002).

In response to previous calls for research (Alam, Reaz, and Ali 2012; Gram-Hanssen and Darby 2018; Marikyan, Papagiannidis, and Alamanos 2019), these results help to provide an answer to the question of how SDPs are connected at scale rather than examining individual practices. A small group of channels have captured a disproportionate share of the recipes (and associated number of installations) within the broader connected SDP network and can be seen organized by degree weight and product class in Figure 5 (C).

Key Insight 2: SDP classes tend to have one dominant service provider that connects to many other product classes. Services with many installations are also the most central in the network.

There is a single giant connected component within the SDP network, meaning all channels are connected through recipes into one broader system. The maximum geodesic distance of the SDP network is 5 (number of "hops" needed to cross the full diameter of the network). Although the network has a relatively low density at .034 (see Table 2), topological measures illustrate that the network is closely connected (average geodesic distance 2.246) and that consumers craft recipes between product categories without restriction. If the network had more than one component, this would reflect a fragmentation of connectivity between particular product types but not so here. The results demonstrate clearly that consumers enact a wide variety of connections between SDPs rather than being restricted by arbitrary classes of products.

Any given product can be connected to any both practically and theoretically. However as shown in Table 3, although consumers may be willing to combine SDPs without prejudice, network topology nonetheless centers on those products with more installations. Table 3 illustrates that the same products are similarly ranked across weighted degree and centrality scores (betweenness and PageRank). There is positive correlation between installations and betweenness centrality scores $(r=$ $.73, p<.5)$ and closeness centrality scores $(r=.81, p<.5)$. As the installations of central nodes increases, probability of connecting to other highly connected nodes also increases and vice versa. Results suggest there is no privileged central position in the network based just on product classes as might for instance have been expected of those products designed explicitly to act as smart home hubs or controllers, for example, Amazon Alexa. Instead, there are clear leaders within different product categories (e.g., lighting, heating, electricity, security), and each of these leading products possesses high degree, weighted degree, and centrality scores. These results provide a clear response to the calls for analysis on how consumers integrate heterogeneous products (Alam, Reaz, and Ali 2012; Gram-Hanssen and Darby 2018).

Key Insight 3: Consumer-crafted recipes tend to connect popular channels with less popular channels. The connected smart home network has a disassortative overall network structure.

Table 2 presents measures of degree assortativity for the SDP network (degree correlation functions). Negative results indicate that nodes with few connections tend to link to highly connected nodes, whereas positive values indicate nodes with similar connectivity tend to connect to each other. The SDP network has a weakly disassortative structure much like other technological networks such as the internet and the World Wide Web (see Newman 2002). 


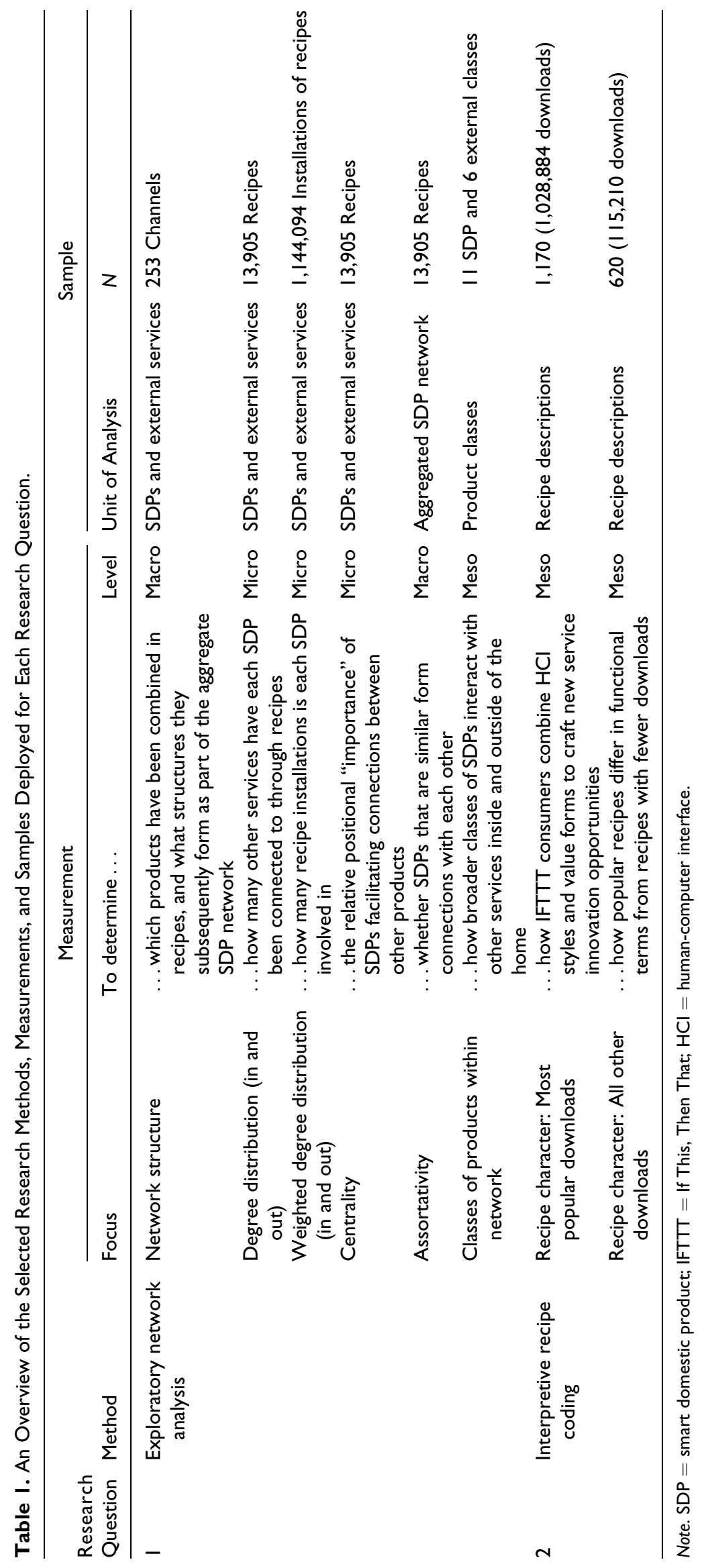


Table 2. Topological Characteristics of the Smart Domestic Product (SDP) Network, Assortativity Measures, and Interaction types for SDP channels.

\begin{tabular}{|c|c|}
\hline \multicolumn{2}{|l|}{ Topological Characteristics of the SDP Network } \\
\hline Channels (nodes) & 253 \\
\hline $\begin{array}{l}\text { Recipes (edges-unique recipes implemented by } \\
\text { users) }\end{array}$ & 13,905 \\
\hline $\begin{array}{l}\text { Total sum weighted degree (number of recipes } \\
\text { implemented) }\end{array}$ & $\mathrm{I}, \mathrm{I} 44,094$ \\
\hline $\begin{array}{l}\text { Average weighted degree (average no. of } \\
\text { implementations per recipe) }\end{array}$ & $\begin{array}{c}82.28(S D= \\
675.99)\end{array}$ \\
\hline $\begin{array}{l}\text { Average degree (average no. of connections } \\
\text { between unique channels) }\end{array}$ & 8.775 \\
\hline Self-loops & 403 \\
\hline $\begin{array}{l}\text { Number of unique channels with reciprocal trigger/ } \\
\text { action relations }\end{array}$ & 66 \\
\hline $\begin{array}{l}\text { Total number of reciprocal relations between } \\
\text { trigger/action channels }\end{array}$ & 148 \\
\hline Connected components & I \\
\hline Maximum geodesic distance (diameter) & 5 \\
\hline Average geodesic distance & 2.246 \\
\hline Graph density & 0.034 \\
\hline Assortativity Measures & $\begin{array}{l}\text { Correlation } \\
\text { Coefficient }\end{array}$ \\
\hline Degree assortativity (undirected) & -.324 \\
\hline Input-input degree assortativity (undirected) & -.132 \\
\hline Input-output degree assortativity (directed) & -.001 \\
\hline Output-input degree assortativity (directed) & -.319 \\
\hline Output-output degree assortativity (directed) & -.116 \\
\hline Interaction Types & Recipe Count \\
\hline $\begin{array}{l}\text { Internal/internal (SDP triggers another SDP within } \\
\text { the home) }\end{array}$ & $3,519(25.31 \%)$ \\
\hline $\begin{array}{l}\text { External/internal (channel outside the home } \\
\text { triggers SDP) }\end{array}$ & $8,351(60.05 \%)$ \\
\hline $\begin{array}{l}\text { Internal/external (SDP triggers channel outside the } \\
\text { home) }\end{array}$ & $2,035(14.64 \%)$ \\
\hline
\end{tabular}

We suggest that SDP network disassortativity is the result of multiple pressures: (1) technological convergence-the phenomenon whereby two or more independent products become integrated (Caviggioli 2016); for example, the smartphone combines technologies from previously disparate products (e.g., telephones, cameras, computers, GPS, and fingerprint scanning) within one unified product; (2) monopolies - in some instances, there is only one product available with particular functionality and API from which to craft new recipes, for example, pet tracking (Whistle Smart Collar); and (3) first mover advantage (Magnusson, Mathing, and Kristensson 2003) - previous service research has shown that companies that involve users in service innovation can gain a competitive commercial advantage (e.g., Chesbrough and Crowther 2006). SDPs ease appropriation by enabling their APIs to encourage user "plugability and configuration" (Dix 2007, p. 2). Those SDPs that first bring an API to market receive the first customer-created recipes, subsequently receive greater exposure than later entrants, and thus benefit from a preferential attachment effect, a phenomenon seen in many other sociotechnical networks (Jeong, Néda, and Barabási 2003).

Key Insight 4: SDP network connections are largely imbalanced at both channel and category level, meaning value is initiated both inside and outside the DIY smart home.

When channels are categorized according to location within or outside the physical domestic boundary, notable imbalances in causal relations are visible (see Table 2). Only $25.3 \%$ of recipes involve combinations of SDPs within the physical domestic boundary, whereas $74.69 \%$ of recipes involve channels outside of the boundary; $60.05 \%$ of recipes involve external triggers where a channel outside the boundary acts upon an SDP, and $14.63 \%$ involve an SDP acting upon a channel outside of the home. Notable imbalances in the direction of causality are also visible at a class and product level. Figure 6 is a heatmap showing normalized trigger/action relations between classes of channels. The results demonstrate the imbalance that most channels maintain, primarily acting as either trigger or action channel. This imbalance holds for the majority of classes.

For example, two external classes "smartphones and ubiquitous computing" and "spatiotemporal indicators and events" have the biggest effect as triggers on SDPs, and yet, the converse relation is far lower when examining how SDPs trigger channels in these categories. Similarly, Figure 6 reveals that the "lighting and shading" category has garnered action support from all categories and yet rarely acts as a trigger. Indeed, lack of reciprocity between classes is most evident in lighting (e.g., Phillips Hue is the most popular action channel with 582,137 installations, yet never acts as a trigger) and in products designed for command-for example, Alexa (out-degree entirely) and Logitech's Harmony (in-degree entirely). Service providers should thus carefully consider how classes of SDPs interrelate more broadly into the service ecosystem in order to create opportunities for strategic alliance through service design.

\section{Research Question 2}

This question concerns functionalities cocreated by combining heterogeneous SDPs in IFTTT. We interpret recipes and develop key insights using both developer and downloader samples of the IFTTT database. We use Woodall, Rosborough, and Harvey's (2018) smart service innovation matrix to categorize functionalities rather than stand-alone products.

Key Insight 5: Consumer-crafted combinations of SDPs are primarily motivated by utilitarian value forms and a preference for supportive human-computer interaction.

The 1,170 recipes taken forward for the interpretive coding exercise at the downloader end of the recipe distribution constitute $8.41 \%$ of the recipe corpus $(13,905$ total $)$ but represent 


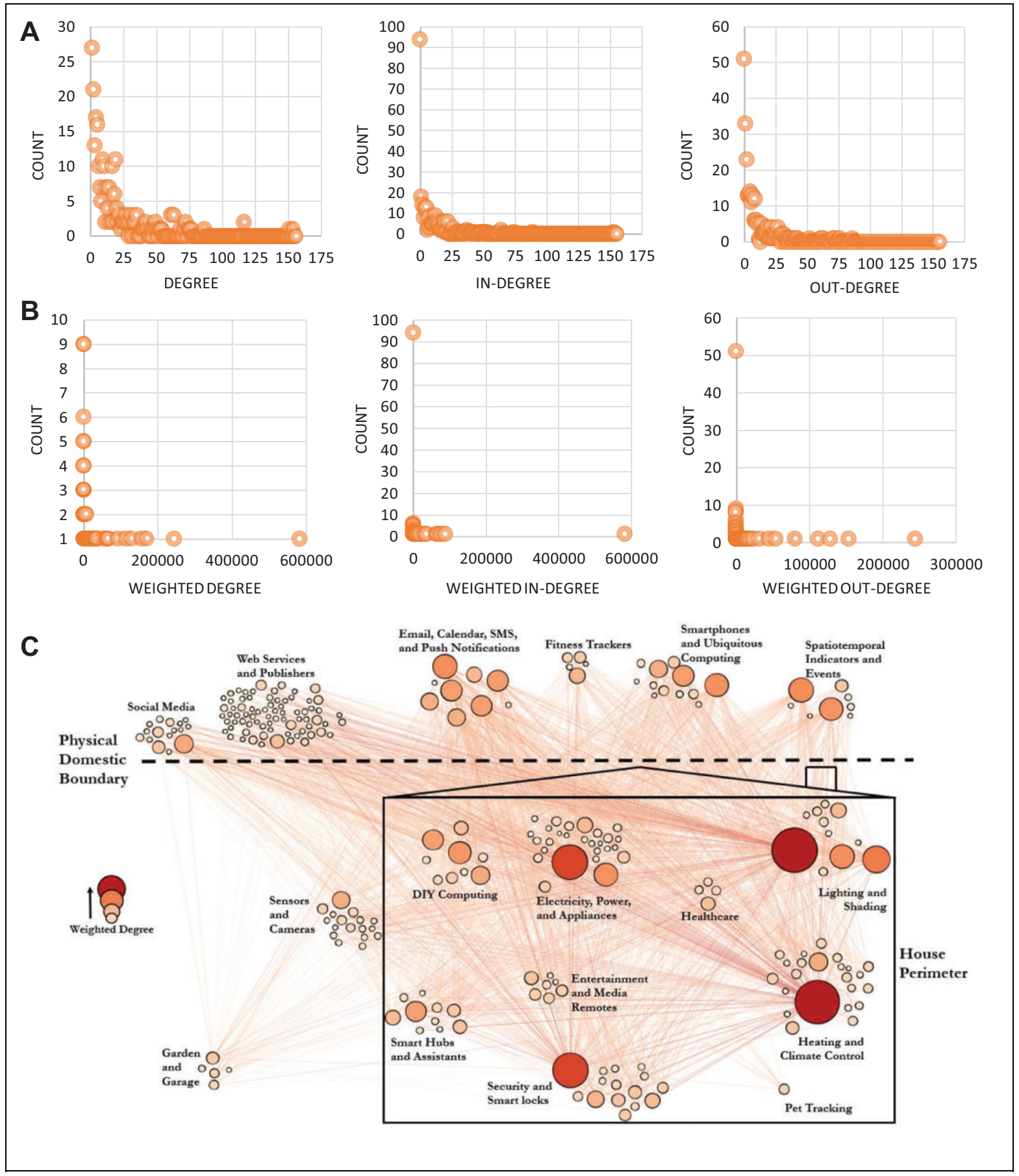

Figure 5. (A) Top row: Smart domestic product network degree distributions, (B) middle row: weighted degree distributions, and (C) bottom row: directed network showing connections between smart domestic products with nodes scaled according to weighted degree (total sum of recipe installations).

$1,028,938$ downloads, equivalent to $89.93 \%$ of the total $(1,144,094)$. Table 4 shows the number of recipes for all combinations of $\mathrm{HCI} /$ value type and is divided (beyond the first column showing the nine possible smart context categories) to give a descriptive analysis related to (a) the downloader segment of the IFTTT population and (b) the developer segment of the population (see Insight 6). The downloader results (derived from recipes downloaded $100+$ times) reveal that the utilitarian/supportive combination, at $66.4 \%$, was the most popular type of recipe for IFTTT users. This was followed by utilitarian/advisory at $23.4 \%$.

The results further show that utilitarian-focused recipes account for $91.2 \%$ of recipes $(66.5 \%$ Utilitarian/Supportive + $23.4 \%$ Utilitarian/Advisory $+1.3 \%$ Utilitarian/Persuasive, representing $89.6 \%$ of download share) while there are only $2 \%$ for transformational value type (1.6\% Transformative/ 


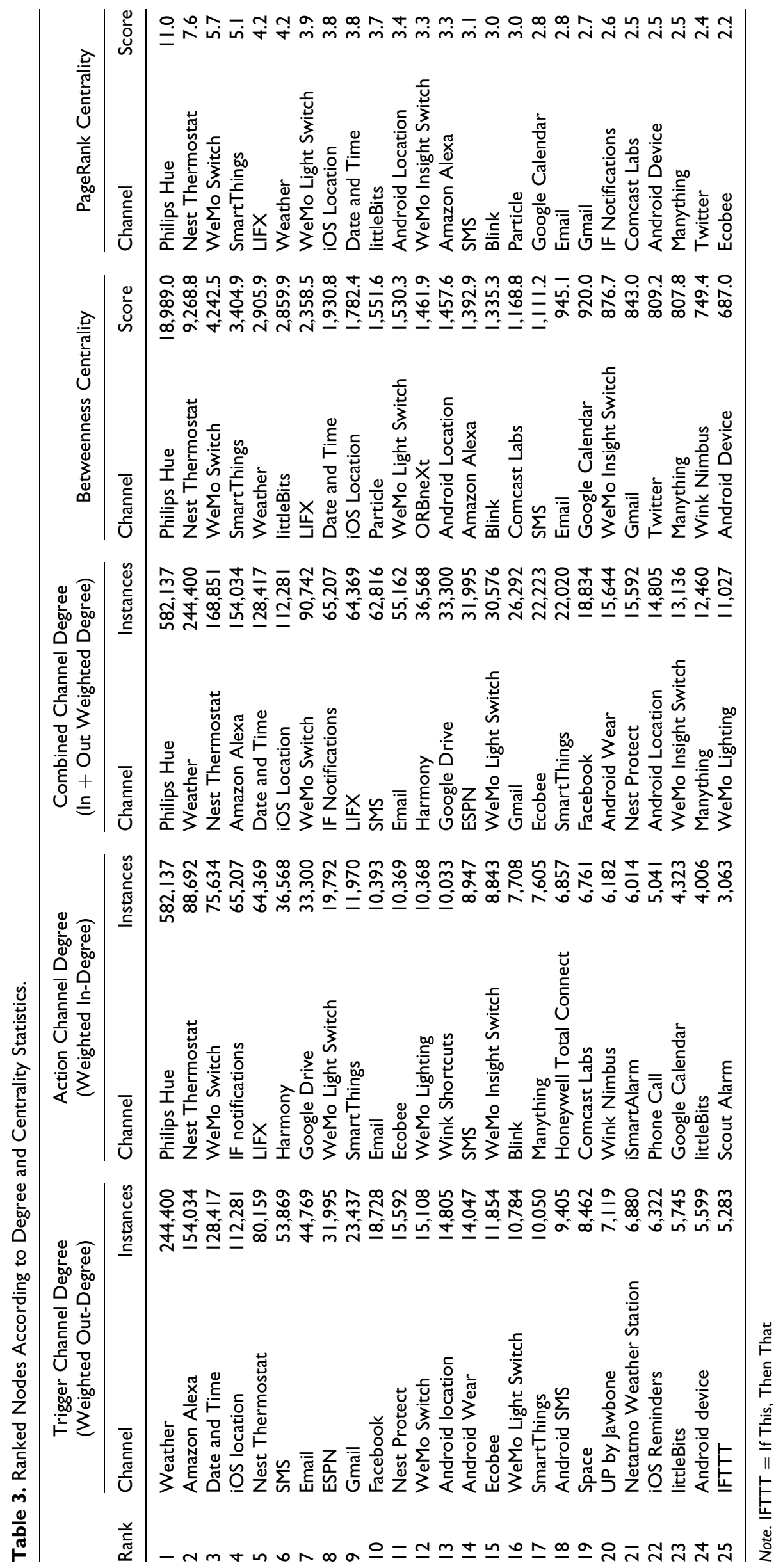




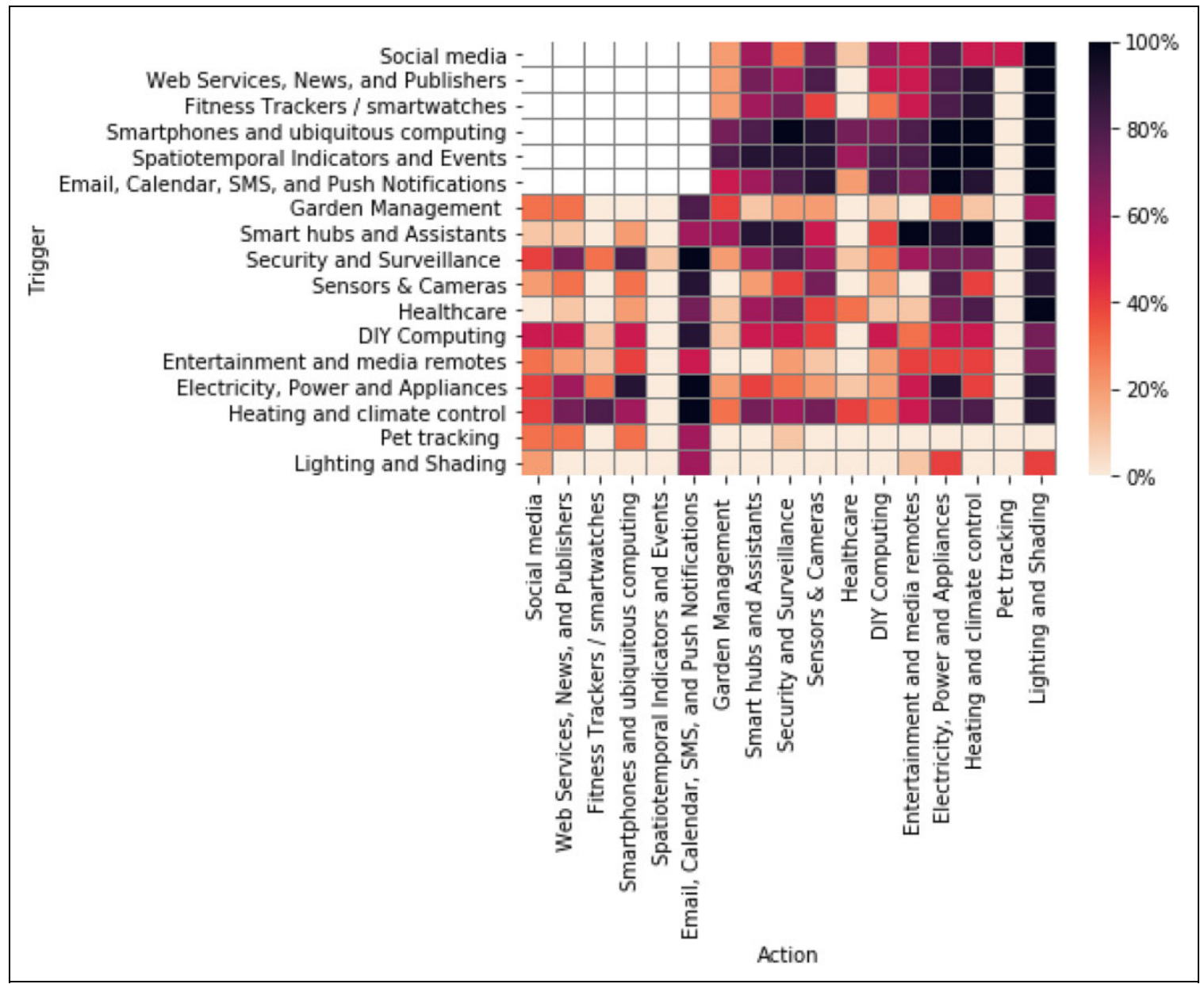

Figure 6. Heatmap showing normalized trigger/action class relations. Note: External/external relations are excluded from the smart domestic product subgraph and are therefore shown as void.

Table 4. Aggregate Descriptive Statistics for Recipes Involving Different $\mathrm{HCI} /$ Value Combinations for Both $100+$ Downloaded Recipes and Once Downloaded Recipes.

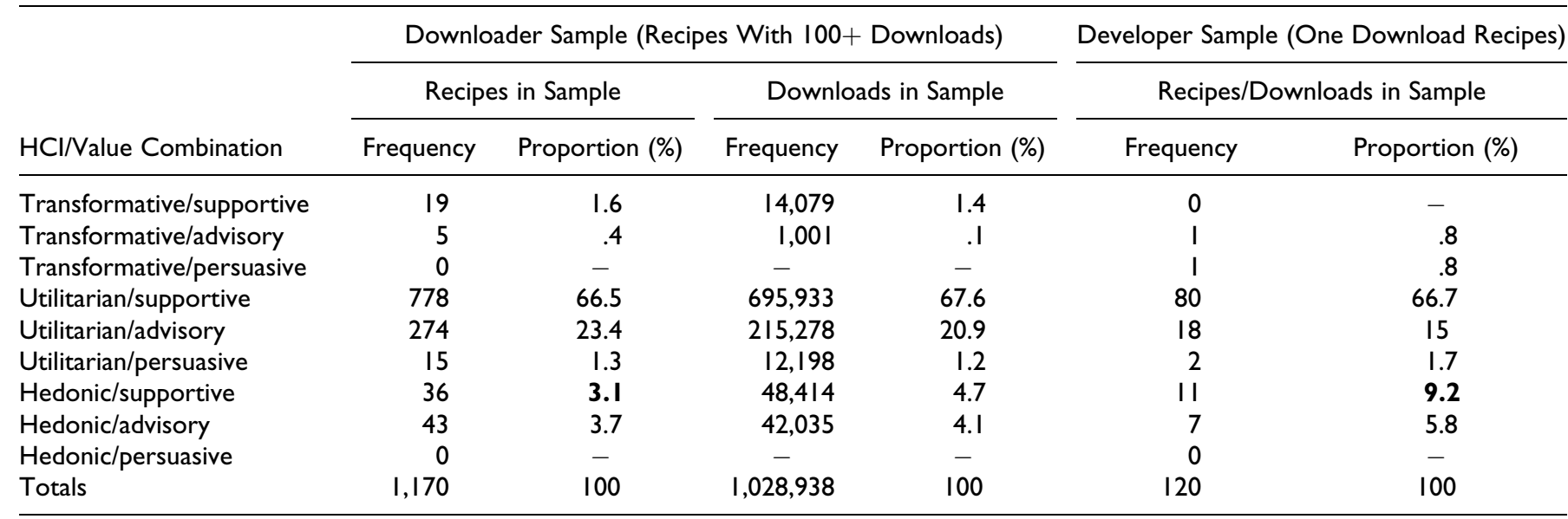

Note. Downloader category has a one to many relationship between number of recipes and downloads, whereas the developer category always has one download per recipe. 


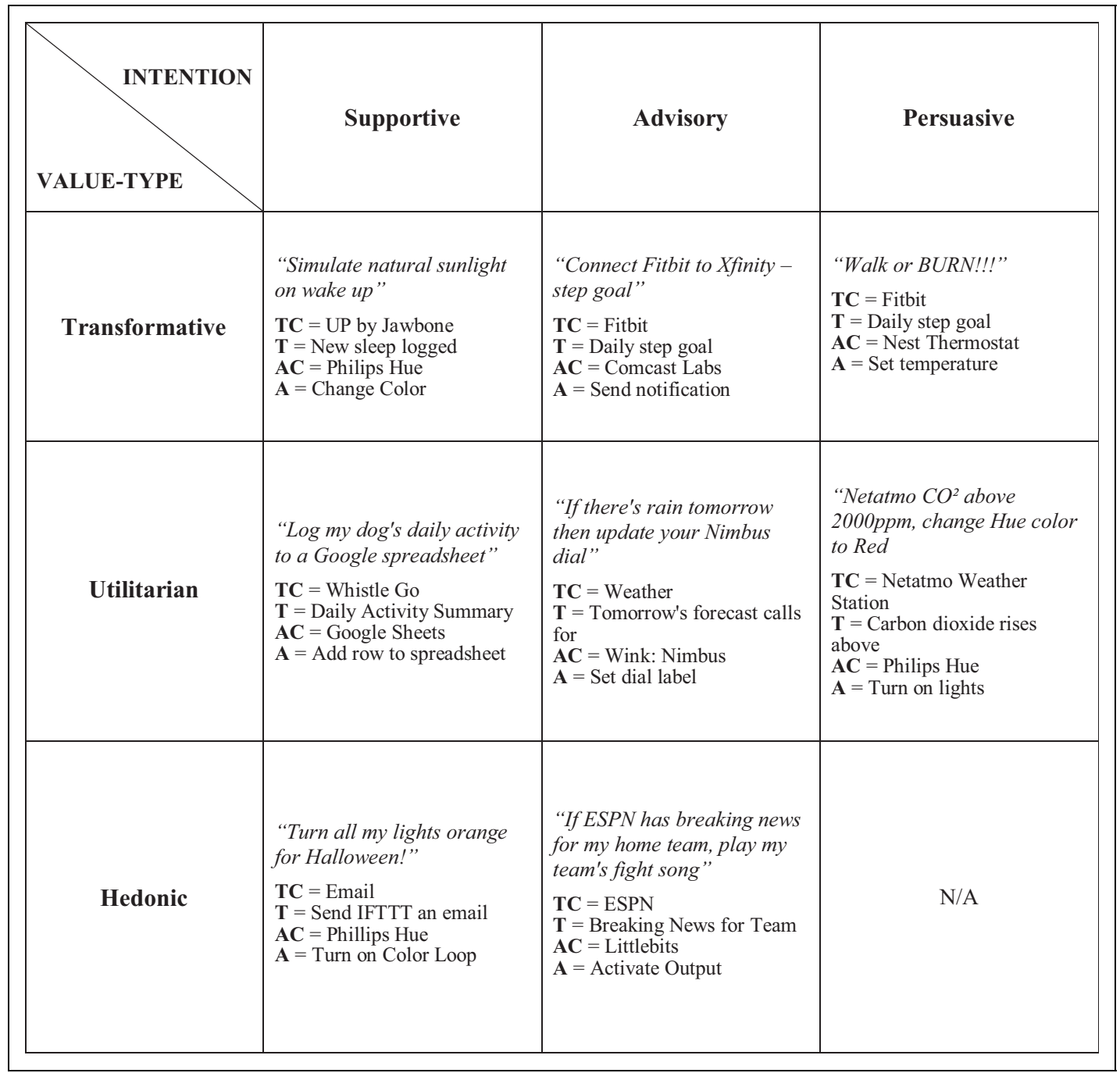

Figure 7. Example recipes—smart service innovation by If This, Then That craft consumers.

Supportive $+.4 \%$ Transformative/Advisory, representing $2 \%$ of total download share). The relative lack of persuasive recipes (just 15 recipes $-1.3 \%$ of download share, and all for utilitarian value type) suggests that though smart products are frequently designed to manipulate owners into acting (e.g., smart watches vibrating to ensure their owners move), when consumers craft their own recipes, the target of automation is generally another product rather than themselves. We therefore do not deny the possibility of hedonic/persuasive recipes but suggest these outcomes are less likely associated with craft consumers who connect products through IFTTT. Figure 7 provides illustrative examples of coded recipes mapped onto the SDP matrix.

Key Insight 6: For one-download recipes, there is a small but statistically significant reduction in utilitarian focus and a compensating increase in hedonism.

To explore whether the developer corpus of recipes differs in character to the downloader corpus, we performed a range of comparative tests between the $100+$ download bin and the 1 ,
2-24, 25-49, 50-74, and 75-99 downloads bins. We used Fisher's exact test for Count Data for testing the null of independence of rows and columns in a contingency table with fixed marginals (Agresti 2002). This was preferred to a standard " $t$ " test given the low download incidence in some cells. The number of replications in the Monte Carlo test was set at 6 million. We then used the false discovery rate adjustment on computed $p$ values (Benjamini and Hochberg 1995) to account for the multiple hypotheses testing involved. We then compared data in the contingency tables $(3 \times 3$ value $/ \mathrm{HCI})$ at matrix, axis, and cell levels.

At the matrix level (all nine cells, value type vs. HCI), we found a significant difference (adjusted $p=.019$ ) between just the one-download subsample (developers) and the $100+$ sample (downloaders). At the axis level (comparing both value type and $\mathrm{HCI}$ independently), we found significant differences on just the value axis, first between the one-download subsample and the $100+$ subsample (adjusted $p=.045$ ) and between the one-download subsample and the 75-99 subsample (adjusted $p$ $=.019$ ). Given that at both matrix and axis levels we found differences between the one-download subsample and the 
$100+$ sample only, and because the difference between the one-download subsample and the 75-99 subsample implied the downloader category was likely wider than first envisaged, we focused cell-level tests on one-download and 100+ downloads only. Here, we converted data into "category of interest" versus rest counts and again ran Fisher's exact test for Count Data, this time testing for an alternative of either "greater than" or "less than" for observed direction of difference in download proportions.

Now disregarding the HCI axis, we focused just on cells in the value axis and evaluated for difference at individual value categories. This led to an observation of differences in both utilitarian $(p=.041)$ and hedonic value types $(p=.019)$. For utilitarian value, there was a lower proportion in the onedownload subsample than in the $100+$ sample $(83.3 \%$ vs. $91.2 \%$ ) and a corresponding increase in the hedonic category (15\% vs. $6.8 \%)$. There were no observed differences for the transformational category. We then evaluated cells using both axes, this time to evaluate for differences at the smallest (HCI $x$ value) increment. Here, we identified a significant difference in proportions $(p=.019)$ for the hedonic/supportive cell only with a higher proportion $(9.2 \%)$ in the one-download subsample than in the $100+$ sample (3.1\%). Given, though, we had previously found no significant differences in the $\mathrm{HCI}$ axis, we concluded the difference was a function of the hedonic aspect of the cell. Evidence at the cell level suggests, therefore, that although developers are significantly more diverse in their activities than are downloaders, they are not substantially so. We reproduce comparative data from the one-download subsample at the developer headed columns in Table 4.

Key Insight 7: When SDPs trigger themselves ("selfloops"), recipes are primarily motivated by a failure to support utilitarian needs and thus highlight opportunities for service innovation.

Thirty-four channels are involved in 403 self-loop recipes, that is, triggering themselves to act (i.e., "daisy chaining"e.g., Blaauw et al. 2014) or triggering a second copy of the same product, so these act in concert in the home; for example, one light bulb turning on if another one does. The number of self-loops rises further to 628 recipes when analysis is conducted at class level (e.g., "heating and climate control") rather than individual channel level. Why should consumers need to link a sensor and an actuator over the Internet that exist within close physical proximity? Self-looping demonstrates that consumers are recrafting product functionality but also that SDPs have been designed for appropriation by "support not control" of features (Dix 2007, p. 2).

Of the 628 self-loops in the data set, we coded 65 at class level (e.g., a security product triggering another security product) of which a subset of 37 were at single product level (e.g., Nest Thermostat triggering itself). The value type coded for these recipes was utilitarian regardless of installation count and occurred in the following combinations: utilitarian/supportive: 58; utilitarian/advisory: 6; utilitarian/persuasive: 1. Self- looping is driven by the failure of SDPs to provide utilitarian value in their basic configurations. Two interesting implications are apparent: (1) self-loops at channel level show redundancy and therefore opportunity to improve SDP design and (2) self-loops provide insight into how people want to pair features from competing technologies together. They therefore show where future technological convergence could assist existing consumers (combining features from previously separate competing products to craft new forms of service innovation and assert functional superiority over rivals).

Evidence of self-loops provide excellent insight for designers looking to capitalize on consumer intelligence for cocreating new functionality. For instance, some recipes instruct smart thermostats to measure room temperature and create an IFTTT alert, which then triggers the same product to adjust the room temperature in response to the alert sent over the Internet. Self-looping recipes highlight redundancy, inefficiency, and possible design flaws that customers are trying to overcome. Self-loops therefore draw attention to the barriers experienced by users during resource integration (Helkkula, Kowalkowski, and Tronvoll 2018; Jaakkola and Alexander 2014). Attentiveness to self-looping recipes is likely to lead to improved design suggestions for individual products and also provides opportunities to plan for further technological convergence between previously heterogeneous sensors and actuators.

Key Insight 8: In the smart DIY eco-system developer and downloader agendas are aligned: Utilitarian recipe design in IFTTT meets service innovation needs in the home.

According to Funk et al. (2017), those wishing to customize their homes for smart capability are most likely to do so using trigger-action programming via websites such as IFTTT. And although this is clearly not the only option available, this offers those with relatively limited programming skills the ability to practice smart-focused craft consumption both for personal and for wider advantage (Ovadia 2014). The results of our coding exercise mirror those of Brich et al. (2017) who conducted a longitudinal study of 12 households in search of insights into end-user programming needs in home automation. They identified respondent preferences for "... automation that would spare them tedious everyday tasks like turning things on or off..." and by contrast note they expressed, "... comparatively little interest in automating entertainment and access control" (p. 20). Developers may initiate individually focused recipes of all types for personal need but can then choose to either make these private or share them as opportunities for further open innovation. And although there were slightly more hedonic recipes in the developer data subset, they perhaps choose primarily to make public those recipes most likely to be "useful" and that allow other DIY smart home craft consumers (most likely downloaders) to improve domestic experience by banishing the mundane to a state of unconscious enactment. 
We note Haraty, McGrenere, and Bunt's (2017) research into developer communities and how results signpost wider community needs. They found developers were reluctant to upload overtly personal or complex customizations and by contrast wished to share those likely to prove more generally useful. In much the same way that academics look to produce outputs that expand their reputation and/or citation count, developers were conscious that popular customizations represented a route to both community approbation and selfapprobation. The objectives of developers and downloaders, therefore, appear to be aligned. We note, though, these may also provide opportunities for downloaders to cocreate - if they should wish it - a value type that has a different core (e.g., hedonic or transformative). In cocreating essentially utilitarian output in IFTTT, developers may be offering downloaders the freedom to cocreate whatever value they wish in the home. For example, the "action" for some recipes is to push a WeMo Switch. And while the most likely case scenario here is to turn on a table lamp, air conditioner, or instigate similarly practical purpose, these could just as easily initiate music or a medical support system. The most innovative IFTTT recipes, therefore, could be those that - through their truly utilitarian nature (potential to provide the greatest happiness to the greatest number) - maximize the opportunities for others to cocreate value of their own choosing. Those recipes with most downloads, therefore, could either be responding to a prescribed utilitarian/supportive need with mass appeal or alternatively offering nonprescribed utility with wider open innovation potential.

\section{Discussion}

\section{Implications for Theory}

We respond to questions posed by Helkkula, Kowalkowski, and Tronvoll (2018) and Jaakkola and Alexander (2014) regarding the ways customers are involved in resource integration. They suggest resource integration cannot be understood simply as the output of a product and user dyad, and our results evidence this. In IFTTT, a broader constellation of people, products, and ideas act via the IoT to trigger service innovation that blurs the distinction between operand and operant resources. Indeed, the results question such a simple binary relationship. IFTTT facilitates a range of functionalities that characterize contemporary smart consumption in the home. As an engagement platform (Ramaswamy 2008), it enables consumers to integrate their ideas with those of organizations and other users for engagement and shared value (Hollebeek and Andreasson 2018). As a platform for open innovation (Chesbrough 2003), it encourages common purpose creativity outside institutional boundaries. Its users exhibit characteristics of prosumers (Toffler 1980), coproducers (Etgar 2008), brand communities (Muniz and Schau 2005), and participatory web cultures (Beer and Burrows 2010), and, as we argue earlier in this article, they are typical of Campbell's (2005) craft consumer.
Results of Research Questions 1 and 2 illustrate how developers use IFTTT to cocreate value for themselves but also to create opportunities for other consumers whose focus is customizing the home. In this respect, IFTTT is typical of Helkkula, Kowalkowski, and Tronvoll's (2018) process-based service innovation archetype. Insights 1-4 illustrate the broad range of recipes crafted by consumers, but Insights 5-8 also demonstrate that utilitarian value-seeking is important as inspiration for new, and frustration with old, forms of service design. In Campbell's (2005) account, craft consumption entails transformation of commodities (in our case SDPs) into personalized or humanized "objects" (for us, heterogeneous SDP combinations) that create new service forms. This "ensemble activity" frees people to consume in expressive new ways and to "acquire control over ... consumption experiences" (Addis and Holbrook 2001, p. 52). While our evidence suggests this is undoubtedly the case-IFTTT recipes reflect individual and/ or domestic proclivities, providing opportunities for "doing" enhanced smartness (Gram-Hanssen and Darby 2018) - we also note that firms are beginning to "piggyback" these consumers, planting their own recipes, infiltrating social networks, and nudging users toward preferred smart configurations. IFTTT users accelerate the proliferation of IoT infrastructure, aiding its mass reach and paradoxically also submitting themselves to manipulation. It is perhaps the case, therefore, that just as postindustrial fragmentation bought with it the inevitability of a consumption/production customer paradigm, digitized prosumption (Paltrinieri and Esposti 2013) has entangled "hero" and "dupe" again subverting consumption hopes.

Further, although consumers might look on occasion to introduce either novelty (hedonic value) or well-being (transformational value) into their smart homes - reflecting, perhaps, the prevailing wisdom of the "experience economy"-our evidence suggests the experiences that consumers frequently want are those that minimize effort and are "ordinary" rather than "extraordinary" (Carù and Cova 2003). Shove (2003) suggests the key objectives for domestic practice are "comfort, cleanliness and convenience" with products (smart or otherwise) increasingly deployed "as essential ingredients in the effective accomplishment of everyday life" (Watson and Shove 2008, p. 69). Removing annoying tasks from the field of consciousness ("supportive" or "calm" technology; Weiser and Brown 1997) appears the key aim for most.

\section{Practical and Managerial Implications}

To our knowledge, the results provide the first large-scale empirical demonstration that popular consumer-crafted combinations of SDPs are primarily motivated toward utilitarian value and a preference for automated tasks performed without conscious attention of users. Our Results section highlighted eight key insights emerging from the research, and we now outline the practical and managerial implications arising from these findings.

Digitized craft consumption opens opportunities for the creative mind, but results suggest automation tends to happen 
for more mundane reasons. IFTTT users opt primarily for utilitarian benefits that are "functional, instrumental, and practical" (Chitturi, Raghunathan, and Mahajan 2008, p. 49). Trigger channels typically initiate the switching on and off of essential home-based functions (e.g., turn on heating before arriving home) or to notify message arrivals (e.g., make a light flash to indicate new email). In this respect, users are essentially conservative, and their "smart" DIY endeavors frequently no more stirring than those conventional home-based DIY activities identified by Watson and Shove (2008) and Wolf and McQuitty (2011).

The findings have clear implications for service design. The SDP network is imbalanced, disassortative, exhibits a longtailed degree distribution, and shows popular services have high centrality across all product category combinations. The topology therefore illustrates that SDPs should not be considered standalone services but members of broader ensembles deliberately "designed for appropriation" (Dix 2007). Design thus suggests products should be conceptualized as part of a service ecosystem (e.g., Akaka and Vargo 2015), a market array characterized by multidirectional resource integration and networked service provision. One key managerial insight arising from our findings concerns service innovation and value propositions. Results show how consumer-crafted service forms within domestic environments can point companies to design for new cocreation opportunities. Skålén et al. (2015, p. 156) suggested that "service innovation must be conducted and value propositions must be evaluated from the perspective of the customers' value creation, the service that customers receive." In the same vein, Barret et al. (2015) argue service innovation is perceived primarily as customer driven and believe that contemporary businesses should actively engage with consumer practices when designing for innovation. The findings from digitized craft consumption reveal how firms can serve their customers more effectively and enhance value-in-use.

\section{Limitations and Future Research}

The results provide unprecedented insight into how consumers craft new forms of service from heterogeneous products. However, there are limitations to the study. Our data set derives from recipes made public by consumers on IFTTT. Although IFTTT is the preeminent service of its kind, it is nonetheless a single case and results should be compared across other platforms also (see Desolda, Ardito, and Matera 2017). Another limitation is that recipe creation is a simple process not requiring user programming knowledge. Thus, a smaller sample of more technically competent users may possibly pair channels without resort to an intermediary service provider, thus circumventing IFTTT. This specialized group of users is not captured by the IFTTT data set, so the prevalence of this practice is unknown. These limitations require further scrutiny to address the demographic, psychographic, and behavioral profiles of people who connect SDPs.
The results of both parts of the study can help guide future research. A temporal evaluation of the SDP network topology could provide insight into whether further technological convergence might affect network disassortativity; that is, products with multiple features may monopolize connections within the home. It would be interesting to monitor the relative number of health care-related SDPs in the database on an ongoing basis. The lack of transformative/persuasive recipes is likely due to the relative absence of products available that are explicitly linked to health care at home, and this will likely increase in future.

The lack of health care products on the market with public APIs integrated into IFTTT is perhaps a consequence of privacy issues that arise when linking products into public networks as shown in previous technical research (Fernandes et al. 2017; Surbatovich et al. 2017). Further insights could be gained by surveying individuals who engage in craft consumption. While speculation abounds regarding consumers' different styles for crafting value, primary data collection would help shed light on this. On a related note, another interesting research direction would be to use longitudinal data to study how IFTTT and its adherents evolve. Our study inherits some of the limitations of cross-sectional research methods (Rindfleisch et al. 2008), and longitudinal study would contribute to enhanced understanding of developing behavior.

As discussed in the Methods of Analysis section, the coding of some recipes was resolved via discussion. Issues arose because in some cases, it proved difficult to choose between persuasive and advisory categories on the HCI side of the SDP typology and between transformative and utilitarian on the value side. In both instances, the most common issue was lack of clarity on user intent. For the bulk of recipes, this was not problematic, and the observed preponderance of utilitarian/ supportive functionality within the recipe corpus is not in question; we believe our "most likely" protocol to be effective. However, when researching beyond the database (within and among users of smart domestic functionality), a more nuanced representation of user value could be determined by introducing a "preventive" category into Woodall, Rosborough, and Harvey's (2018) typology $y$-axis. This would help capture instances where users were neither seeking enhanced wellbeing (transformative value) nor just utilitarian value but instead wished to prevent deterioration of existing wellbeing. This could apply, for example, to maintaining versus losing weight or to notifications concerning deteriorating versus dangerous weather.

For persuasive versus advisory categories, collaborative resolution proved easier. The coding procedure showed that IFTTT users were unlikely to exert unwelcome pressure on themselves. However, given the increasing prevalence of firm-generated content on IFTTT, and the invasion of "smart interactive services" (Wünderlich, Wangenheim, and Bitner 2013) into the home, this might not always be the case. We thus hypothesize a further HCI category for consideration in the broader context of SDP service design. We call this perfidious rather than "persuasive" HCI, characterized as advice but with 
persuasive intent. Thus, a user-initiated alert may merely imply time to wake up or time to watch TV but if firm-initiated alert could imply time to "watch that ad" or to "buy more stuff." We suggest, therefore, that in research contexts where intent can be clearly defined, a four-by-four rather than three-by-three typology would provide a more nuanced characterization of smart functionality and user motivation. If the best computer truly is a "quiet, invisible servant," we should nevertheless scrutinize who they are said to serve.

\section{Declaration of Conflicting Interests}

The author(s) declared no potential conflicts of interest with respect to the research, authorship, and/or publication of this article.

\section{Funding}

The author(s) disclosed receipt of the following financial support for the research, authorship, and/or publication of this article: We would like to thank Nottingham Trent University for financial support for some data analysis costs.

\section{ORCID iD}

John Harvey (D) https://orcid.org/0000-0003-4188-1900

Georgiana Nica-Avram (D) https://orcid.org/0000-0003-4550-837X

\section{Supplemental Material}

Supplemental material for this article is available online.

\section{References}

Addis, Michela and Morris B. Holbrook (2001), "On the Conceptual Link between Mass Customisation and Experiential Consumption: An Explosion of Subjectivity," Journal of Consumer Behaviour: An International Research Review, 1 (1), 50-66.

Agresti, A. (2002), Categorical Data Analysis, 2nd ed. New York: Wiley, 91-101.

Akaka, Melissa Archpru and Stephen L. Vargo (2015), "Extending the Context of Service: From Encounters to Ecosystems," Journal of Services Marketing, 29 (6/7), 453-462.

Alam, Muhammad Raisul, Mamun Bin Ibne Reaz, and Mohd Alauddin Mohd Ali (2012), "A Review of Smart Homes - Past, Present, and Future," IEEE Transactions on Systems, Man, and Cybernetics, Part C (Applications and Reviews), 42 (6), 1190-1203.

Albert, Réka and Albert-László Barabási (2002), "Statistical Mechanics of Complex Networks," Reviews of Modern Physics, 74 (47), 1-54.

Antons, David and Christoph F. Breidbach (2018), "Big Data, Big Insights? Advancing Service Innovation and Design with Machine Learning," Journal of Service Research, 21 (1), 17-39.

Ashton, Kevin (2009), “That 'Internet of Things' Thing," RFID Journal, 22 (7), 97-114.

Babin, Barry J., William R. Darden, and Mitch Griffin (1994), "Work and/or Fun: Measuring Hedonic and Utilitarian Shopping Value," Journal of Consumer Research, 20 (4), 644-656.

Barabási, Albert-László (2016), Network Science. Cambridge, England: Cambridge University Press.

Barrett, Michael, Elizabeth Davidson, Jaideep Prabhu, and Stephen L. Vargo (2015), "Service Innovation in the Digital Age: Key
Contributions and Future Directions," MIS Quarterly, 39 (1), 135-154.

Bastian, Mathieu, Sebastien Heymann, and Mathieu Jacomy (2009), "Gephi: An Open Source Software for Exploring and Manipulating Networks," in Proceedings of the Third International AAAI Conference on Weblogs and Social Media, Eyton Adar, Matthew Hurst, Tim Finin, Natalie Glance, Nicolas Nicolov and Belle Tseng, eds. (May 17-20), San Jose, CA, 361-362. The AAAI Press.

Batagelj, Vladimir and Andrej Mrvar (1998), "Pajek-Program for Large Network Analysis," Connections, 21 (2), 47-57.

Beer, David and Roger Burrows (2010), "Consumption, Prosumption and Participatory Web Cultures: An Introduction," Journal of Consumer Culture, 10 (1), 3-12.

Benjamini, Yoav and Yosef Hochberg (1995). "Controlling the False Discovery Rate: A Practical and Powerful Approach to Multiple Testing," Journal of the Royal Statistical Society: Series B (Methodological), 57(1), 289-300.

Bitner, Mary Jo, Amy L. Ostrom, and Matthew L. Meuter (2002), "Implementing Successful Self-Service Technologies," Academy of Management Perspectives, 16 (4), 96-108.

Blaauw, D., D. Sylvester, P. Dutta, Y. Lee, I. Lee, S. Bang, and Y. Kim (2014), "IoT Design Space Challenges: Circuits and Systems," in Proceedings of the Symposium on VLSI Technology (VLSI-Technology): Digest of Technical Papers (June 1-2), Institute of Electrical and Electronics Engineers, Honolulu, HI.

Blocker, Christopher P. and Andrés Barrios (2015), "The Transformative Value of a Service Experience," Journal of Service Research, 18 (3), 265-283.

Bolton, Ruth, Anders Gustafsson, Janet McColl-Kennedy, Nancy Sirianni, and David Tse (2014), "Small Details that Make Big Differences: A Radical Approach to Consumption Experience as a Firm's Differentiating Strategy," Journal of Service Management, 25 (2), 253-274.

Borgatti, Stephen P., Martin G. Everett, and Jeffrey C. Johnson (2018), Analyzing Social Networks. London, England: Sage.

Borgatti, Stephen P., Martin G. Everett, and Linton C. Freeman (2002), Ucinet for Windows: Software for Social Network Analysis. Harvard, MA: Analytic Technologies.

Brich, Julia, Marcel Walch, Michael Rietzler, Michael Weber, and Florian Schaub (2017), "Exploring End User Programming Needs in Home Automation," ACM Transactions on Computer-Human Interaction (TOCHI), 24 (2), 1-35, Article 11.

Cambridge Dictionary (2019), Cambridge, England: Cambridge University Press, (accessed June 24, 2019), [available at https://diction ary.cambridge.org/dictionary/].

Campbell, Collin (2005), "The Craft Consumer: Culture, Craft and Consumption in a Postmodern Society," Journal of Consumer Culture, 5 (1), 23-42.

Carù, Antonella and Bernard Cova (2006), "How to Facilitate Immersion in a Consumption Experience: Appropriation Operations and Service Elements." Journal of Consumer Behaviour: An International Research Review, 5 (1), 4-14.

Carù, Antonella and Bernard Cova (2003), "Revisiting Consumption Experience: A More Humble But Complete View of the Concept," Marketing Theory, 3 (2), 267-286. 
Caviggioli, Federico (2016), “Technology Fusion: Identification and Analysis of the Drivers of Technology Convergence Using Patent Data," Technovation, 55-56, 22-32.

Chandler, Jennifer D. and Steven Chen (2015), "Prosumer Motivations in Service Experiences," Journal of Service Theory and Practice, 25 (2), 220-239.

Chandler, Jennifer D. and Robert F. Lusch (2015), "Service Systems: A Broadened Framework and Research Agenda on Value Propositions, Engagement, and Service Experience," Journal of Service Research, 18 (1), 6-22.

Chase, Jim (2013), "The Evolution of the Internet of Things," Texas Instruments, (accessed June 24, 2019), [available at http://www.tij. co.jp/jp/lit/ml/swrb028/swrb028.pdf].

Chesbrough, Henry and Adrienne Kardon Crowther (2006), "Beyond High Tech: Early Adopters of Open Innovation in Other Industries," R\&D Management, 36 (3), 229-236.

Chesbrough, Henry (2003), Open Innovation: The New Imperative for Creating and Profiting from Technology. Boston, MA: Harvard Business School Press.

Chitturi, Ravindra, Rajagopal Raghunathan, and Vijay Mahajan (2008), "Delight by Design: The Role of Hedonic versus Utilitarian Benefits," Journal of Marketing, 72 (3), 48-63.

Cohen, J. (1992), “A Power Primer,” Psychological Bulletin, 112 (1), 155.

Cole, Steven James (2018), "Use Value as a Cultural Strategy against Over-Commodification: A Durkheimian Analysis of Craft Consumption within Virtual Communities," Sociology, 52 (5), 1052-1068.

Cova, Bernard, Daniele Dalli, and Detlev Zwick (2011), "Critical Perspectives on Consumers' Role as 'Producers': Broadening the Debate on Value Co-Creation in Marketing Processes," Marketing Theory, 11 (3), 231-241.

Cova, Bernard and Daniele Dalli (2009). "Working Consumers: The Next Step in Marketing Theory?" Marketing Theory, 9 (3), 315-339.

Das, Gopal, Amaradri Mukherjee, and Ron Smith (2018), "The Perfect Fit: The Moderating Role of Selling Cues on Hedonic and Utilitarian Product Types," Journal of Retailing, 94 (2), 203-216.

De Keyser, Arne, Sarah Köcher, Linda Alkire, Cédric Verbeeck, and Jay Kandampully (2019), "Frontline Service Technology Infusion: Conceptual Archetypes and Future Research Directions," Journal of Service Management, 30 (1), 156-183.

De Nooy, Wouter, Andrej Mrvar, and Vladimir Batagelj (2018), Exploratory Social Network Analysis with Pajek: Revised and Expanded Edition for Updated Software, 46. Cambridge, England: Cambridge University Press.

Desolda, Giuseppe, Carmelo Ardito, and Maristella Matera (2017), "Empowering End Users to Customize Their Smart Environments: Model, Composition Paradigms, and Domain-Specific Tools," ACM Transactions on Computer-Human Interaction (TOCHI), 24 (2), 1-52, Article 12.

De Swert, Knut (2012), "Calculating Inter-Coder Reliability in Media Content Analysis Using Krippendorff's Alpha," Center for Politics and Communication, 1-15, (accessed July 7, 2019), [available at
https://www.polcomm.org/wp-content/uploads/ICR01022012. pdf].

Dix, A. (2007), "Designing for Appropriation," in Proceedings of the 21st British HCI Group Annual Conference on People and Computers: HCI ... But Not as We Know It-Vol. 2, Ormerod Tom and Corina Sas, eds., BCS Learning \& Development Ltd., Swinton, England, 27-30.

Dorogovtsev, Sergey N. and Jose F. F. Mendes (2002), "Evolution of Networks," Advances in Physics, 51 (4), 1079-1187.

Elliot, Esi A. (2016), "Craft Consumption and Consumer Transformation in a Transmodern Era," Journal of Business Research, 69 (1), 18-24.

Etgar, Michael (2008), "A Descriptive Model of the Consumer CoProduction Process," Journal of the Academy of Marketing Science, 36 (1), 97-108.

Fernandes, Earlence, Amir Rahmati, Jaeyeon Jung, and Atul Prakash (2017), "Decoupled-IFTTT: Constraining Privilege in TriggerAction Platforms for the Internet of Things," ArXiv preprint arXiv:1707.00405. Ithaca, NY: Cornell University.

Firat, A. Fuat and Alladi Venkatesh (1995), "Liberatory Postmodernism and the Re-Enchantment of Consumption." Journal of Consumer Research, 22 (3), 239-267.

Fogg, Brian J. (1998), "Persuasive Computers: Perspectives and Research Directions," in Proceedings of the SIGCHI Conference on Human Factors in Computing Systems, Karat Clare-Marie, Arnold Lund, Joëlle Coutaz and John Karat, eds. (April 18-23), ACM Press/Addison-Wesley, Los Angeles, 225-232.

Funk, Mathias, Lin-Lin Chen, Shao-Wen Yang, and Yen-Kuang Chen (2018), "Addressing the Need to Capture Scenarios, Intentions and Preferences: Interactive Intentional Programming in the Smart Home," International Journal of Design, 12 (1), 53-66.

Galvagno, Marco and Danieli Dalli (2014), "Theory of Value CoCreation: A Systematic Literature Review," Managing Service Quality, 24 (6), 643-683.

Gram-Hanssen, Kirsten and Sarah J. Darby (2018), “"Home Is Where the Smart Is'? Evaluating Smart Home Research and Approaches against the Concept of Home," Energy Research \& Social Science, 37 (3), 94-101.

Gu, Tao, Hung Keng Pung, and Qing Zhang Da (2015), “A ServiceOriented Middleware for Building Context-Aware Services," Journal of Network and Computer Applications, 28 (1), 1-18.

Gustafsson, Anders, Hannah Snyder, and Lars Witell (2020), "Service Innovation: A New Conceptualization and Path Forward." Journal of Service Research, 23 (2), 111-115.

Hand, Martin and Elizabeth Shove (2007), "Condensing Practices: Ways of Living with a Freezer," Journal of Consumer Culture, 7 (1), 79-104.

Haraty, Mona, Joanna McGrenere, and Andrea Bunt (2017), “Online Customization Sharing Ecosystems: Components, Roles, and Motivations," in Proceedings of the 2017 ACM Conference on Computer Supported Cooperative Work and Social Computing, Charlotte P. Lee and Steve Poltrock, eds., Association of Computing Machinery, New York, 2359-2371.

Helkkula, Anu, Christian Kowalkowski, and Bård Tronvoll (2018), "Archetypes of Service Innovation: Implications for Value Cocreation," Journal of Service Research, 21 (3), 284-301. 
Hibbert, Sally, Heidi Winklhofer, and Mohamed Sobhy Temerak (2012), "Customers as Resource Integrators: Toward a Model of Customer Learning," Journal of Service Research, 15 (3), 247-261. Hilton, Toni, Tim Hughes, and David Chalcraft (2012), "Service CoCreation and Value Realisation," Journal of Marketing Management, 28 (13-14), 1504-1519.

Hofacker, Charles F., Edward Carl Malthouse, and Fareena Sultan (2016), "Big Data and Consumer Behavior: Imminent Opportunities," Journal of Consumer Marketing, 33 (2), 89-97.

Hollebeek, Linda D. and Tor W. Andreassen (2018), "The SD Logic-Informed 'Hamburger' Model of Service Innovation and Its Implications for Engagement and Value," Journal of Services Marketing, 32 (1), 1-7.

Hoy, Matthew B. (2015), "If This Then That: An Introduction to Automated Task Services," Medical Reference Services Quarterly, 34 (1), 98-103.

Huang, Ming-Hui and Roland T. Rust (2018), “Artificial Intelligence in Service," Journal of Service Research, 21 (2), 155-172.

Humphreys, Ashlee and Kent Grayson (2008), “The Intersecting Roles of Consumer and Producer: A Critical Perspective on CoProduction, Co-Creation and Prosumption," Sociology Compass, 2 (3), 963-980.

Jaakkola, Elina and Matthew Alexander (2014), “The Role of Customer Engagement Behavior in Value Co-Creation: A Service System Perspective," Journal of Service Research, 17 (3), 247-261.

Jeong, Hawoong, Zoltan Néda, and Albert-László Barabási (2003), "Measuring Preferential Attachment in Evolving Networks," EPL (Europhysics Letters), 61 (4), 567-572.

Jörling, Moritz, Robert Böhm, and Stefanie Paluch (2019), "Service Robots: Drivers of Perceived Responsibility for Service Outcomes." Journal of Service Research, 22 (4), 404-420. doi:10.1177/ 1094670519842334.

Kang, U., Spiros Papadimitriou, Jimeng Sun, and Hanghang Tong (2011), "Centralities in Large Networks: Algorithms and Observations," in Proceedings of the 2011 SIAM International Conference on Data Mining, Society for Industrial and Applied Mathematics, Bing Liu, Huan Liu, Chris Clifton, Takashi Washio and Chandrika Kamath, eds. (April 28-30), Mesa, AZ, 119-130. Society for Industrial and Applied Mathematics.

Knott, Stephen (2013), "Design in the Age of Prosumption: The Craft of Design after the Object," Design and Culture, 5 (1), 45-67.

Kosnik, Elisabeth (2018), "Production for Consumption: Prosumer, Citizen-Consumer, and Ethical Consumption in a Postgrowth Context," Economic Anthropology, 5 (1), 123-134.

Krippendorff, Klaus (2018), Content Analysis: An Introduction to Its Methodology, 4th ed. Thousand Oaks, CA: Sage.

Laurel, Brenda and S. Joy Mountford (1990), The Art of HumanComputer Interface Design. Boston, MA: Addison-Wesley Longman Publishing.

Magnusson, Peter R., Jonas Matthing, and Per Kristensson (2003), "Managing User Involvement in Service Innovation: Experiments with Innovating End Users," Journal of Service Research, 6 (2), $111-124$
Marikyan, Davit, Savvas Papagiannidis, and Eleftherios Alamanos (2019), "A Systematic Review of the Smart Home Literature: A User Perspective," Technological Forecasting and Social Change, 138 (1), 139-154.

Meuter, Matthew L., Amy L. Ostrom, Robert I. Roundtree, and Mary Jo Bitner (2000). "Self-Service Technologies: Understanding Customer Satisfaction with Technology-Based Service Encounters," Journal of Marketing, 64 (20), 50-64.

Mi, Xianghang, Feng Qian, Ying Zhang, and XiaoFeng Wang (2017), "An Empirical Characterization of IFTTT: Ecosystem, Usage, and Performance," in Proceedings of the 2017 Internet Measurement Conference, Steve Uhlig and Olaf Maennel, eds. (November 1-3), ACM, London, England, 398-404. New York, USA: Association for Computing Machinery..

Mick, David G. (2006), "Meaning and Mattering through Transformative Consumer Research," Advances in Consumer Research, 33 (1), 1-4.

Miranda, Javier, Niko Mäkitalo, Jose Garcia-Alonso, Javier Berrocal, Tommi Mikkonen, Carlos Canal, and Juan M. Murillo (2015), "From the Internet of Things to the Internet of People," IEEE Internet Computing, 19 (2), 40-47.

Muniz, Albert, M., Jr, and Hope Jensen Schau (2005), "Religiosity in the Abandoned Apple Newton Brand Community," Journal of Consumer Research, 31 (4), 737-747.

Newman, Mark E. J. (2002), “Assortative Mixing in Networks.” Physical Review Letters, 89 (20), 208701.

Novak, Thomas P. and Donna L. Hoffman (2019), "Relationship Journeys in the Internet of Things: A New Framework for Understanding Interactions between Consumers and Smart Objects," Journal of the Academy of Marketing Science, 47 (2), 216-237.

Olick, Diana (2017), "Why 2017 Will Finally Be the Year of the Smart Home: Consumers Figure It Out," CNBC Reality Check, (accessed April 17, 2019), [available at https://www.cnbc.com/2017/01/04/ why-2017-will-finally-be-the-year-of-the-smart-home-consumersfigure-it-out.html].

Ovadia, Steven (2014), "Automate the Internet with "If This Then That" (IFTTT)," Behavioral and Social Sciences Librarian, 33 (4), 208-211

Paltrinieri, Roberta and Piergiorgio Esposti (2013), "Processes of Inclusion and Exclusion in the Sphere of Prosumerism," Future Internet, 5 (1), 21-33.

Prahalad, Coimbatore K. and Venkatram Ramaswamy (2000), "CoOpting Customer Competence," Harvard Business Review, 78 (1), 79-90.

Ramaswamy, Venkat (2008), “Co-Creating Value through Customers' Experiences: The Nike Case," Strategy \& Leadership, 36 (5), 9-14.

Rindfleisch, Aric, Alan J. Malter, Shankar Ganesan, and Christine Moorman (2008), "Cross-Sectional versus Longitudinal Survey Research: Concepts, Findings, and Guidelines," Journal of Marketing Research, 45 (3), 261-279.

Ritzer, George (2016), "The Dehumanized Consumer: Does the Prosumer Offer Some Hope," in Being Human in a Consumer Society, Alejandro Néstor and Martínez García, eds. Abingdon, OX: Routledge, 25-40. 
Robles, Rosslin, Tai-Hoon Kim, Diane Cook, and Sajal Das (2010), "A Review on Security in Smart Home Development," International Journal of Advanced Science and Technology, 15 (2), 13-22.

Shove, Elizabeth (2003), "Converging Conventions of Comfort, Cleanliness and Convenience," Journal of Consumer Policy, 26 (4), 395-418.

Skålén, Per, Johanna Gummerus, Catharina Von Koskull, and Peter R. Magnusson (2015), "Exploring Value Propositions and Service Innovation: A Service-Dominant Logic Study," Journal of the Academy of Marketing Science, 43 (2), 137-158.

Stojkoska, Biljana L. Risteska and Kire V. Trivodaliev (2017), “A Review of Internet of Things for Smart Home: Challenges and Solutions," Journal of Cleaner Production, 140 (3), 1454-1464.

Surbatovich, Milijana, Jassim Aljuraidan, Lujo Bauer, Anupam Das, and Limin Jia (2017), "Some Recipes Can Do More Than Spoil Your Appetite: Analyzing the Security and Privacy Risks of IFTTT Recipes," in Proceedings of the 26th International Conference on World Wide Web, Rick Barrett, Rick Cummings, Eugene Agichtein and Evgeniy Gabrilovich, eds. (April 3-7), Perth, Australia, 15011510. International World Wide Web Conferences Steering Committee.

Toffler, Alvin (1980), The Third Wave. New York: Bantam Books. Ur, Blase, Melwyn Pak Yong Ho, Stephen Brawner, Jiyun Lee, Sarah Mennicken, Noah Picard, Diane Schulze, and Michael L. Littman (2016), "Trigger-Action Programming in the Wild: An Analysis of 200,000 IFTTT Recipes," in Proceedings of the 2016 CHI Conference on Human Factors in Computing Systems, Kaye Jofish and Allison Druin, eds. (May 7-12), San Jose, CA, 3227-3231. Association for Computing Machinery.

Van Doorn, Jenny, Martin Mende, Stephanie M. Noble, John Hulland, Amy L. Ostrom, Dhruv Grewal, and J. Andrew Petersen (2017), "Domo Arigato Mr. Roboto: Emergence of Automated Social Presence in Organizational Frontlines and Customers' Service Experiences," Journal of Service Research, 20 (1), 43-58.

Vargo, Stephen L. and Robert F. Lusch (2006), "Service-Dominant Logic: What It Is, What It Is Not, What It Might Be," in The Service Dominant Logic of Marketing: Dialog, Debate, and Directions, Robert F. Lusch and Stephen L. Vargo, eds. New York: Routledge, 43-56.

Vargo, Stephen L. and Robert F. Lusch (2004), "Evolving to a New Dominant Logic for Marketing," Journal of Marketing, 68 (1), $1-17$.

Watson, Matthew and Elizabeth Shove (2008), "Product, Competence, Project and Practice: DIY and the Dynamics of Craft Consumption," Journal of Consumer Culture, 8 (1), 69-89.

Weiser, Mark and John Seely Brown (1997), "The Coming Age of Calm Technology," in Beyond Calculation, Peter J. Denning and Robert M. Metcalfe, eds. New York: Springer, 75-85.

Weiser, Mark (1996), "Computer Science Challenges for the Next 10 Years.” YouTube. Rutgers University, https://www.youtube.com/ watch? $\mathrm{v}=7 \mathrm{jwLWosmmjE}$ (accessed July 7, 2019).

Weiser, Mark (1991), "The Computer for the 21st Century," Scientific American, 265 (3), 94-105.
Wilson, Charlie, Tom Hargreaves, and Richard Hauxwell-Baldwin (2017), "Benefits and Risks of Smart Home Technologies," Energy Policy, 103 (4), 72-83.

Wolf, Marco and Shaun McQuitty (2011), "Understanding the Do-ItYourself Consumer: DIY Motivations and Outcomes," AMS Review, 1 (3-4), 154-170.

Woodall, Tony, Julie Rosborough, and John Harvey (2018), "Proposal, Project, Practice, Pause: Developing a Framework for Evaluating Smart Domestic Product Engagement," AMS Review, 8 (1-2), 58-74.

Wünderlich, Nancy V., Kristina Heinonen, Amy L. Ostrom, Lia Patricio, Rui Sousa, Chris Voss, and Jos GAM Lemmink (2015), “Futurizing' Smart Service: Implications for Service Researchers and Managers," Journal of Services Marketing, 29 (6-7), 442-447.

Wünderlich, Nancy V., Florian V. Wangenheim, and Mary Jo Bitner (2013), "High Tech and High Touch: A Framework for Understanding User Attitudes and Behaviors Related to Smart Interactive Services," Journal of Service Research, 16 (1), 3-20.

\section{Author Biographies}

John Harvey is an assistant professor in marketing at Nottingham University Business School and is the economic networks lead within the Neo-demographic Laboratory for Analytics in Business (N/LAB).

Mojtaba Poorrezaei is an award-winning principle lecturer in marketing at Nottingham Trent Business School, and he is the program leader for MSc marketing suite. His research is concerned with customer experience and interactive customer/brand relationship. $\mathrm{He}$ is currently working on a research project concerned with the conceptualization of experienced respect through the customer engagement cycle. He has published in International Journal of Market Research and has presented in several national and international conferences.

Tony Woodall is a senior lecturer in marketing at Nottingham Business School, Nottingham Trent University, where his teaching concerns both consumer and marketer behavior, primarily in service settings. Prior and current research interests/projects focus on how consumers aggregate, experience, and perceive service value and on the nature/role of both marketing and the marketer in contemporary contexts-increasingly, in technology-mediated contexts. Tony has published on these topics in a range of journals including the European Journal of Marketing, Journal of Business Ethics, Studies in Higher Education, International Business Review, Marketing Theory, and AMS Review.

Georgiana Nica-Avram is a research associate at the University of Nottingham. Her background is multidisciplinary with a $\mathrm{PhD}$ in digital economy and MSc in marketing communications. She has a long-standing interest in approaches that facilitate social change in the areas of food sharing, food waste, outdoor advertising, and destitution. She is particularly interested in the ways that machine 
learning methods can illuminate individuals' experiences with digital technologies.

Gavin Smith is an assistant professor at N/LAB, University of Nottingham. He holds a $\mathrm{PhD}$ in computer science, and his research focuses on understanding, predicting, and summarizing human behavior through the application and development of novel machine learning and data mining methods. His often interdisciplinary work has been published internationally within a range of leading publications including top computer science venues such as the IEEE International Conference on Data Mining (ICDM), IEEE International Conference on Pervasive Computing and Communications (PERCOM), the IEEE International Conference on Big Data.

Tolu Ajiboye is a $\mathrm{PhD}$ candidate of marketing at the Nottingham Business School. He has an MSC in international business from
Nottingham Business School and an undergraduate degree from Nottingham Trent University. His research focuses on customer engagement behavior through social media platforms in the context of SMEs in the United Kingdom Fashion Industry.

Karina Kholodova is a $\mathrm{PhD}$ student conducting research on consumer engagement with brand-related content on social media at Nottingham Business School.

Kai Zhu is a senior lecture in marketing at Nottingham Business School. His research interests include consumer decision making, consumer behavior analysis from a temporal perspective, and applications of survival analysis in consumer research. He is particularly interested in consumers' information processing behavior and capacity on digital platforms and how these influence their decision-making outcome. 